\title{
A NOVEL MODEL OF IN VITRO OSTEOCYTOGENESIS INDUCED BY RETINOIC ACID TREATMENT
}

\author{
D. Mattinzoli ${ }^{1}$, P. Messa ${ }^{1,2}$, A. Corbelli ${ }^{1,3}$, M. Ikehata ${ }^{1}$, C. Zennaro ${ }^{4}$, S. Armelloni ${ }^{1}$, M. Li $^{1}$, L. Giardino ${ }^{1}$
} and M.P. Rastaldi ${ }^{1, *}$

\author{
'Renal Research Laboratory, Fondazione IRCCS Ca' Granda Ospedale Maggiore Policlinico \& Fondazione D'Amico \\ per la Ricerca sulle Malattie Renali, Milano, Italy \\ ${ }^{2}$ Department of Nephrology, Dialysis and Renal Transplant, Fondazione IRCCS Ca' Granda Ospedale Maggiore \\ Policlinico, Milano, Italy \\ ${ }^{3}$ MIA Consortium for Image Analysis, La Bicocca University, Milan, Italy \\ ${ }^{4}$ Renal Physiopathology Laboratory, Department of Medical, Surgical and Health Sciences, University of Trieste, \\ Trieste, Italy
}

\begin{abstract}
Despite recent research which more and more stresses the importance of osteocytes in regulating bone and systemic mineral metabolism, current molecular and functional knowledge of osteocyte properties are still incomplete, mostly due to limited availability of in vitro models.

Osteocytes are terminally differentiated dendritic cells, and therefore are not easy to obtain and maintain in primary cultures. As an alternative, osteocyte differentiation can be induced by progressive osteoblast embedding in mineralised extracellular matrix. In this model, which is suitable for reproduction of bone development, the presence of calcified matrix prevents several cell biological methods from being used. Therefore, the osteocyte-like MLO-Y4 cell line continues to be the most widely used cellular system.

Here we show that treatment of primary osteoblasts or MC3T3-E1 cells with retinoic acid generates a homogeneous population of ramified cells with osteocyte features, as confirmed by morphological and molecular analyses. The first morphological changes are detectable in primary cells after 2 days of treatment, and in the cell line after 4 days of treatment. Differentiation is complete in 5 and 10 days, respectively, with progressive development of dendrites, loss of the ability to produce extracellular matrix, down-regulation of osteoblast markers, and up-regulation of osteocyte-specific molecules, most notably among them sclerostin.

Compared to other published protocols, our method has a number of advantages. It is easy to perform and does not require special instrumentation, it is highly reproducible, and rapidly generates a mature osteocyte population in the complete absence of extracellular matrix, allowing the use of these cells for unlimited biological applications.
\end{abstract}

Key words: Retinoic acid; melatonin; osteoblast; osteocyte; sclerostin.

*Address for correspondence:

Maria Pia Rastaldi

Renal Research Laboratory

Fondazione IRCCS Ca' Granda Ospedale Maggiore Policlinico

Via Pace 9, I-20122, Milano, Italy

Telephone Number: 00390255033879

FAX Number: 00390255033878

E-mail: mariapia.rastaldi@policlinico.mi.it

\section{Introduction}

Osteocytes are the most abundant cell type in bone, derived from progressive transformation of a subpopulation of committed osteoblasts, which progressively embed in newly formed matrix. During embedding, committed osteoblasts change phenotype according to an active program dictated by a specific pattern of gene expression, that leads to regulated polarised formation of multiple dendrites and expression of specific proteins, relevant to bone mass regulation, phosphate homeostasis, hypoxia resistance and cytoskeletal organisation (Bonewald, 2011).

The cell body of mature osteocytes is contained in bone lacunae and the extended branched dendrites reside in tiny channels called canaliculi, forming an intricate web that makes multiple contacts not only with other osteocytes, but also with other bone cell types, bone marrow, and blood vessels. Through the interstitial fluid contained in lacunae and canaliculi, osteocytes are also ultimately connected to the circulating system, therefore they can influence not only local but also systemic events, and vice versa, their behaviour can be regulated by both local and systemic changes (Cheng and Hulley, 2010).

Given the central role in bone and system physiology, numerous research efforts have been carried out to reveal the biological properties of osteocytes and understand their contribution to health and disease states. In recent years, a number of technical improvements, such as the generation of tissue- and cell-specific transgenic animals, the use of powerful microscopy techniques and of highthroughput molecular screening, have favoured these analyses, providing novel information on osteocytespecific molecular expression patterns and identifying key regulators of osteocyte function (Paic et al., 2009; Dallas and Bonewald, 2010).

The difficulty of culturing osteocytes remains a current issue, due to the high level of differentiation of this cell type. Therefore, novel in vitro methodologies could enhance the possibilities of studying these cells and improve knowledge of osteocyte biology. To be widely usable, such methods should be easy to reproduce, would not require special instrumentation or very long times to reach cell maturation.

Since osteocytes derive from differentiation of committed osteoblasts, this process has been largely studied in vitro, where osteoblast differentiation can be induced by matrix scaffolds (Boukhechba et al., 2009; Krishnan et al., 2010) and a variety of substances. Among molecules 
that are known to influence osteoblast differentiation, such as parathyroid hormone (Tian et al., 2011), oestrogens (Mizutani et al., 1998), Bone Morphogenetic Proteins (Suzawa et al., 1999), and Fibroblast Growth Factors (Marie, 2012), melatonin and retinoic acid have been extensively studied and are known to play important roles in bone physiology and physiopathology.

Melatonin is an indoleamine primarily secreted by the pineal gland, but also synthesised in other organs, such as the retina, the gastrointestinal tract, and noteworthy, the bone marrow. It has a regulatory role in several physiological processes, from hypothalamic control of circadian rhythms to modulation of the immune system (Sánchez-Barceló et al., 2010). Human osteoblasts express melatonin receptors, and numerous experiments have concordantly shown that pharmacological, micromolar doses of melatonin increase osteoblast proliferation, alkaline phosphatase activity, expression of type I collagen, osteopontin, bone sialoprotein, osteocalcin, and mineralised matrix formation (Roth et al., 1999).

All-trans retinoic acid (ATRA) is an active metabolic product of vitamin $\mathrm{A}$, and a master regulator of gene expression. It exerts its effects on gene transcription by binding to nuclear retinoic acid receptors (RARs). RARs bind to DNA as heterodimers with the retinoid X receptors (RXRs), ultimately leading to modulation of retinoic acid-responsive target genes (Ross et al., 2000). Though in vitro analyses of retinoic acid effects on osteoblasts have reported contradicting results in terms of maturation and mineralisation (Song et al., 2005; Cohen-Tanugi and Forest, 1998), both melatonin and ATRA seem to accelerate maturation of the murine pre-osteoblast MC3T3-E1 cell line (Roth et al., 1999; Nagasawa et al., 2005).

This cell line has been extensively analysed and appears to be a very good model of bone development because its growth, in the presence of ascorbic acid and glycerol phosphate, invariably passes through three distinct stages of proliferation, differentiation and mineralisation, with well-defined stage-specific gene expression patterns (Quarles et al., 1992).

Ascorbic acid and glycerol phosphate have also been shown to favour and accelerate deposition of calcified extracellular matrix in primary rodent osteoblasts (Stangenberg et al, 2005), which can be obtained in sufficient numbers by well-established isolation procedures.
Here we describe that addition of ATRA to MC3T3-E1 cells, or to primary cells isolated from mouse calvaria, if applied at a precise maturation stage on cells plated at a defined density, induces a phenotype switch that results in a homogeneous population of ramified cells. The osteocyte nature of these cells is confirmed by extensive morphological and molecular characterisation, and the effect seems highly ATRA-specific because it is not obtained by application of melatonin in the same conditions.

\section{Materials and Methods}

\section{MC3T3-E1 cell line}

The MC3T3-E1 cell line, subclone 4 (Wang et al., 1999), a pre-osteoblast cell line established from normal newborn mouse calvaria, was obtained from the American Type Culture Collection (ATCC) (LGC Standards, Sesto San Giovanni, Milan, Italy). 400,000 cells were initially plated in a $75 \mathrm{~cm}^{2}$ flask, and were cultivated in alphaMEM medium (Invitrogen, Milan, Italy), supplemented with $10 \%$ FBS (Sigma-Aldrich, Milan, Italy) and $1 \%$ streptomycin/penicillin (Sigma-Aldrich). When cells reached $80 \%$ confluence, $50 \mu \mathrm{g} / \mathrm{mL}$ ascorbic acid and $3 \mathrm{mM}$ glycerol 2-phosphate disodium salt hydrate (SigmaAldrich) were added and the medium was changed every other day.

After 5 days of incubation with ascorbic acid/glycerol phosphate (AA/GP), cells were trypsinised and re-seeded in $25 \mathrm{~cm}^{2}$ flasks, according to their subsequent utilisation. A first group was plated at a density of $10,000 \mathrm{cells} / \mathrm{cm}^{2}$ and continued to be cultivated in the same conditions, namely basal medium plus AA/GP, whereas melatonin (Sigma-Aldrich) was added to basal medium plus AA/GP in a second group of cells, plated at 10,000 cells $/ \mathrm{cm}^{2}$ as well. Retinoic acid (All Trans Retinoic Acid, ATRA, from Sigma-Aldrich) was added to basal medium plus AA/GP in a third group of cells.

In ATRA-treated cells, we found that the initial cell density was relevant to the optimal development of cell processes and intercellular contacts. While a starting density of 10,000 cells $/ \mathrm{cm}^{2}$ was too high, because it impaired proper development of cell processes, too low cell numbers resulted in premature cell death, due to the absence of intercellular contacts. After these experiments, the optimal density was set at 5000 cells $/ \mathrm{cm}^{2}$.

\begin{abstract}
Fig. 1. Western Blot, negative control. The left panel shows positivity of protein extracts from primary osteoblasts for Cx43 (lane 1, $40 \mathrm{kD}$ ) and tubulin (lane 1, $52 \mathrm{kD}$ ), utilised as loading control. The right panel, lane 2, displays results of the same experiment conducted after the antibody anti-Cx43 was pre-incubated with the blocking peptide [Mouse Connexin 43 (Cx43) Control/blocking peptide, Alpha Diagnostic International, Società Italiana Chimici, Rome, Italy)]. Presence of the tubulin band guarantees for protein loading.
\end{abstract}

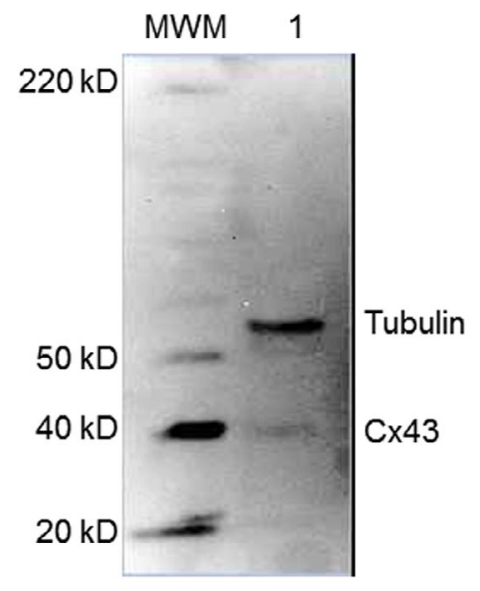

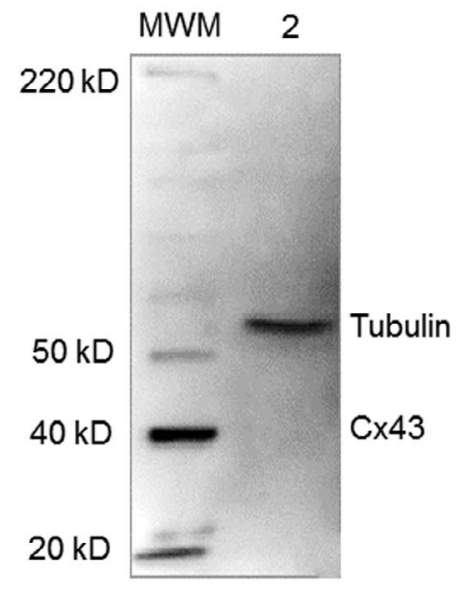

www.ecmjournal.org 
Studies were conducted at several time points, namely after 4, 5, 8, 10, 12, 15, 20 and 25 days of incubation.

\section{Primary osteoblasts}

Primary osteoblasts were isolated from 3-4 day-old C57BL6 mice, according to a well-established procedure (Dodig et al., 1996), with minor modifications.

Briefly, calvaria were removed from 6 to 10 mice, parietal bones were cut in two halves, and subjected to four sequential digestion steps ( $15 \mathrm{~min}$ each, at $\left.37^{\circ} \mathrm{C}\right)$ in HBSS medium (HBSS, no calcium, no magnesium, no phenol red, Gibco/Life Technologies, Milan, Italy) supplemented with $0.05 \%$ CollagenaseP (Roche Applied Science, Monza, Italy.) and $0.1 \%$ Trypsin $(2.5 \%$ Trypsin $10 \mathrm{X}$, no phenol red, Gibco/Life Technologies).

Cells from the first digestion were discarded, whereas cells from the 2 nd to the 4 th digestion were placed in alphaMEM medium (Invitrogen), supplemented with $10 \%$ FBS (Sigma-Aldrich) and $1 \%$ streptomycin/penicillin (SigmaAldrich), then pooled, and seeded in a $25 \mathrm{~cm}^{2}$ flask. After $24 \mathrm{~h}$ medium was changed to remove debris from dead cells. Thereafter, medium was changed every other day.

When cells reached confluence, they were trypsinised and seeded at a density of 10,000 cells $/ \mathrm{cm}^{2}$ in $25 \mathrm{~cm}^{2}$ flasks. A first group of cells continued to be cultivated in the same conditions (basal medium plus AA/GP). ATRA was added to basal medium plus AA/GP in a second group of cells. The higher seeding density of ATRA-treated primary cells, as compared to the cell line, was due to the observed stronger sensitivity of primary cells to ATRA. Primary cells were monitored daily to assess morphology, and were utilised after 5 and 7 days of treatment.

\section{Melatonin and retinoic acid treatment}

To optimise culture conditions, melatonin and ATRA dosedependent $(1 \mu \mathrm{M}, 10 \mu \mathrm{M}, 20 \mu \mathrm{M}, 50 \mu \mathrm{M}$ and $100 \mu \mathrm{M})$ and time-dependent preliminary analyses were carried out.

Based on these first experiments, $50 \mu \mathrm{M}$ melatonin and $10 \mu \mathrm{M}$ ATRA were used in all subsequent studies conducted on MC3T3-E1 cells. Morphological changes started after 4 days of treatment.

In primary cells, $1 \mu \mathrm{M}$ ATRA did not have any effect, but $10 \mu \mathrm{M}$ ATRA resulted in too rapid aging and cell death, and optimal ATRA concentration in our hands was $5 \mu \mathrm{M}$. Morphological changes started after $48 \mathrm{~h}$ of treatment.

All experiments using ATRA were conducted in a darkened room to prevent ATRA inactivation.

\section{Microscopy and immunofluorescence}

For transmission electron microscopy (TEM) and immunofluorescence, cells were plated according to the above conditions, on Petri dishes or coverslips. For TEM, cells were fixed in a mixture of $4 \%$ paraformaldehyde and $2 \%$ glutaraldehyde in phosphate buffer, $0.12 \mathrm{M}$ $\left(\mathrm{Na}_{2} \mathrm{HPO}_{4} \cdot 2 \mathrm{H}_{2} \mathrm{O}+\mathrm{NH}_{2} \mathrm{PO}_{4} \cdot 1 \mathrm{H}_{2} \mathrm{O}-\mathrm{pH} 7.4\right)$, post-fixed in $1 \%$ osmium tetroxide in $0.1 \mathrm{M}$ cacodylate buffer $\left(\mathrm{C}_{2} \mathrm{H}_{6} \mathrm{AsNaO}_{2} \times 3 \mathrm{H}_{2} 0\right)$, dehydrated, and embedded in Epon-Araldite resin. After staining with uranyl acetate $\left[\left(\mathrm{UO}_{2}\left(\mathrm{CH}_{3} \mathrm{COO}\right)_{2} \cdot 2 \mathrm{H}_{2} \mathrm{O}\right)\right.$ in $100 \%$ ethanol] and $0.4 \%$ lead citrate $\left[\left(\mathrm{C}_{12} \mathrm{H}_{10} \mathrm{O}_{14} \mathrm{~Pb}_{3}\right)\right.$ in distilled water], cells were observed under a CM10 Philips microscope (FEI,
Eindhoven, The Netherlands). All reagents and grids for electron microscopy were from Electron Microscopy Sciences (Società Italiana Chimici, Rome, Italy).

For atomic force microscopy (AFM), cells grown on plastic coverslips were fixed with $2.5 \%$ glutaraldehyde in cacodylate buffer $0.1 \mathrm{M}$ for $10 \mathrm{~min}$ at room temperature, washed three times in cacodylate buffer, partially dehydrated (up to $70 \%$ ) and allowed to dry. Characterisation of cell topography was performed using the A100-CLAFM (A.P.E. Research, Area Science Park, Trieste, Italy) in NonContact Mode, by silicon nitride cantilevers with spring constant of $40 \mathrm{~N} / \mathrm{m}$ and curvature radius of $10 \mathrm{~nm}$ (NSC15 type, MikroMasch, Tallinn, Estonia).

For indirect immunofluorescence (Li et al., 2011), cells were alternatively fixed in $4 \%$ paraformaldehyde or cold acetone, depending on the primary antibody to be applied. After fixation, cells were incubated with the primary antibody [rabbit anti-collagen type 1 (Abcam, Cambridge, UK), mouse anti-connexin 43 (Sigma-Aldrich), rabbit anti-FGF23 (Santa Cruz Biotechnology, Heidelberg, Germany), rabbit anti-E11/gp38 (a gift from D. Kerjaschki, University of Vienna, Austria), goat anti-osteoprotegerin (goat anti-OPG, Santa Cruz Biotechnology), and rabbit anti-sclerostin (Sigma-Aldrich)]. As secondary fluorescentlabelled antibodies, we used the following: Alexa Fluor 488 (or 546) goat anti-rabbit IgG, Alexa Fluor 488 (or 546) goat anti-mouse IgG highly cross-adsorbed (Invitrogen), Alexa Fluor 546 donkey anti-goat IgG. Specificity of $\mathrm{Ab}$ labelling was demonstrated by the lack of staining after substituting proper control immunoglobulins (rabbit primary $\mathrm{Ab}$ isotype control and mouse primary $\mathrm{Ab}$ isotype control, both from Invitrogen; goat isotype control, from Abcam) for the primary antibodies. Direct staining with Rhodamine-labelled phalloidin (SigmaAldrich) was used to analyse filamentous actin. DAPI (Sigma-Aldrich) was utilised as nuclear counterstaining. Slides were mounted with Fluorsave aqueous mounting medium (Calbiochem, Merck Chemicals, Nottingham, UK). Images were acquired by a Zeiss Axioscope 40FL microscope, equipped with AxioCam MRc5 digital video camera and immunofluorescence apparatus (Carl Zeiss, Arese, Mi, Italy), and recorded by AxioVision software 4.3 (Carl Zeiss).

\section{Cell proliferation assay}

To quantify proliferating cells, we used a 5-bromo-2deoxyuridine (BrdU) cell proliferation assay kit (Cell Signalling Technology, Euro Clone, Milan, Italy), according to the manufacturer's instructions.

Briefly, MC3T3-E1 cells after 8 days of treatment and primary cells after 4 days of treatment were plated ( 8 replicates per each condition) at the above described densities (namely, 10.000 cells $/ \mathrm{cm}^{2}$ for all cell groups but ATRA-treated MC3T3-E1, seeded at 5000 cells $/ \mathrm{cm}^{2}$ ) in 96-well plates (one plate was used per each time point) and left to adhere for $24 \mathrm{~h}$. Then cell medium was replaced by medium containing $10 \mu \mathrm{M}$ BrdU.

After 24 and $48 \mathrm{~h}$, medium was removed and replaced by the fixing/denaturing solution provided by the kit, kept at room temperature for $30 \mathrm{~min}$, and then removed. Cells were subsequently incubated with the primary mouse anti- 
BrdU antibody at room temperature for $1 \mathrm{~h}$, followed by washing and application of the secondary HRP (horseradish peroxidase)-conjugated anti-mouse IgG. After washing, 3,3',5,5'-Tetramethylbenzidine (TMB) substrate was added to reveal peroxidase activity, followed by the TMB Stop solution included in the kit. Absorbance was read at $450 \mathrm{~nm}$ immediately after adding the Stop solution.

\section{Alizarin red staining and extraction methods}

Alizarin red staining solution $(1 \mathrm{mg} / \mathrm{mL}, \mathrm{pH} 5.5$, SigmaAldrich) was added to ethanol-fixed cells (70\% ethanol for $10 \mathrm{~min}$ ), and washed with tap water after $30 \mathrm{~min}$. After images were taken, cells were destained by $60 \%$ perchloric acid at $4{ }^{\circ} \mathrm{C}$. Optical density of the supernatant was evaluated by spectrophotometry at $450 \mathrm{~nm}$ wavelength. To normalise values for cell number, Janus green whole cell stain was then added to the cell preparation for $10 \mathrm{~min}$. Cells were washed with tap water and the staining was evaluated by spectrophotometry at $615 \mathrm{~nm}$ wavelength. Cells were seeded at the concentrations described above and 3 to 5 replicates were studied per each treatment and time point.

\section{Alkaline phosphatase}

$0.1 \mathrm{mg}$ fast $\mathrm{red} / \mathrm{naph}$ thol solution was added to $4 \%$ paraformaldehyde-fixed cells for $30 \mathrm{~min}$, and results were evaluated by light microscopy. As a positive control, the method was applied to normal mouse kidney sections, where proximal tubules and the Bowman's capsule are known to contain the enzyme. Negative controls were performed after blocking alkaline phosphatase with $5 \mathrm{mM}$ levamisole, as described (Goldstein et al., 1980). Cells were seeded at the concentrations described above and 3 replicates were analysed per each treatment and each time point.

\section{ELISA tests}

Osteocalcin and FGF23 levels in the supernatants were evaluated by ELISA (mouse osteocalcin ELISA kit, Biomedical Technologies, Stoughton, MA, USA; and mouse FGF23 ELISA kit, Immutopics International, Pantec, Torino, Italy), according to the manufacturer's instructions. The Osteocalcin ELISA test has a sensitivity of $1 \mathrm{ng} / \mathrm{mL}$, with intra-assay variation of $6 \%$ and interassay variation of $8 \%$. Mouse FGF23 ELISA has a sensitivity of $4 \mathrm{pg} / \mathrm{mL}$, intra-assay variation of $6.2 \%$ and inter-assay variation of $5.9 \%$.

ELISA tests were conducted on MC3T3-E1 cells (3 replicates per treatment condition and each time point).

mRNA extraction and RT-PCR (Real Time RT-PCR) Total RNA was extracted by Trizol (Invitrogen) and precipitated by chloroform-isopropil alcohol, washed in $75 \%$ ethanol, resuspended in nuclease free-water, then treated with DNase, resuspended, and quantified by spectrophotometry. cDNA was prepared from $1 \mu \mathrm{g}$ RNA using the iScript Select cDNA Synthesis Kit and oligo(dt)20 primers (Bio-Rad, Segrate, Milan, Italy).

Multiple Real Time RT-PCR data of molecules related to bone maturation were obtained using the mouse
Osteogenesis Array Kit (SABiosciences, Qiagen, Milan, Italy), according to the manufacturer's instructions. For these experiments, RNA was obtained from 3 replicates (three $25 \mathrm{~cm}^{2}$ flasks) per each condition at one time point. Specifically, MC3T3-E1 cells were studied at 15 days, whereas primary cells were studied at 7 days of treatment.

Part of the MC3T3-E1 mRNA was separately used to evaluate FGF23 and OPG expression, with the following primers: FGF23: forward 5'GAT CCC CAC CTC AGT TCT CA3'; reverse 5'CCG GAT AGG CTC TAG CAG TG3'; OPG: forward 5'GCC ACG CAAAAG TGT GGA AT3'; reverse 5'TTT GGT CCC AGG CAA ACT GT3'; data were normalised against the expression of GAPDH (forward primer 5'GGT ATC GTG GAA GGA CTC ATG A3'; reverse primer 5'GGC CAT CCA CAG TCT TCT G3'). After assessment of primer specificity by RT-PCR (not shown), Real Time RT-PCR was run with iQ Sybr Green Supermix (Bio-Rad) on a MyIQ instrument (Bio$\mathrm{Rad}$ ), and data were analysed by the IQ5 Bio-Rad Software.

\section{Protein isolation and Western blot}

After cell lysis in RIPA buffer [25 mM Tris-HCl pH 7.6, $150 \mathrm{mM} \mathrm{NaCl}, 1 \% \mathrm{NP}-40$ (nonyl phenoxy polyethoxyl ethanol), $1 \%$ sodium deoxycholate, $0.1 \%$ SDS (sodium dodecyl sulphate)], protein extracts were separated on a SDS-PAGE and transferred by electroblotting on a PVDF membrane (ImmunBlot PVDF membrane, Bio-Rad). After blocking, each membrane was incubated with the primary antibody, followed by the anti-mouse or anti-rabbit HRPconjugated secondary antibody, and positive reaction products were identified by chemiluminescence (BM Chemiluminescence Western Blotting Kit, Roche, Monza, Italy). Loading controls were conducted with antibodies directed against alpha-tubulin (Abcam), beta-actin (SigmaAldrich) and cofilin (Abcam). Negative controls were performed by loading buffer instead of protein extracts or by pre-incubating the primary antibody with a blocking peptide (Fig. 1).

Images were digitally acquired by Chemidoc XRS instrument (Bio-Rad) and analysed by Quantity One software (Bio-Rad).

\section{In-cell ELISA}

To get quantification of protein expression data, we used the In-Cell ELISA colorimetric detection kit (Thermo Scientific, Euroclone, Milan, Italy), according to the manufacturer's instructions.

To this purpose, 3 replicates of each cell type were plated at the same seeding densities as described above on a 96well plate. After $4 \%$ buffered paraformaldehyde fixation, cells were sequentially incubated with permeabilisation buffer, quenching solution and blocking buffer. The primary antibody was then added, followed by the HRPconjugated secondary antibody and TMB substrate. The reaction was stopped after 15 min with the TMB stop solution and absorbance was immediately measured at $450 \mathrm{~nm}$ wavelength. After washing, Janus green whole-cell stain was added for $5 \mathrm{~min}$. Careful washing was followed by addition of elution buffer and absorbance was read at $615 \mathrm{~nm}$. Replicate background measurements were 
subtracted from all $450 \mathrm{~nm}$ measures. The resulting A450 values were then normalised to the $\mathrm{A} 615$ values to account for differences in cell number.

\section{Statistical analyses}

Experiments were conducted on 3 to 8 replicates per each condition and time point, as specified above. Data were expressed as mean \pm standard deviation (SD), and Student's $t$-test was applied to determine significance $(p<0.05)$.

For Real Time RT-PCR, relative RNA abundance was determined using the comparative $\mathrm{Ct}$ method (Livak and Schmittgen, 2001).

Real Time PCR Array data analysis was conducted by using the online software resource at: http://pcrdataanalysis. sabiosciences.com/pcr/arrayanalysis.php. For MC3T3-E1 cells, fold change of melatonin (group 1) and ATRA (group 2) results were compared to AA/GP cells taken as control group. Results from primary cells were evaluated separately, and fold change of ATRA data (group 1) were compared to AA/GP expression data (control group).

Fold change error bars, calculated by the online software, represent the standard deviation $(\sigma)$ of the fold change (FC), according to the following formula: $\sigma_{\mathrm{FC}}=\mathrm{FC}$ $* \ln 2 * \operatorname{sqrt}\left(\sigma_{\mathrm{x}}^{2} / \mathrm{n}_{\mathrm{x}}+\sigma_{\mathrm{y}}{ }^{2} / \mathrm{n}_{\mathrm{y}}\right)$.

$P$ values were calculated based on a Student's $t$-test of the replicate $2^{\wedge}(-$ Delta $C t)$ values for each gene in the control group and treatment groups, and $p$ values $<0.05$ were considered significant.

\section{Results}

\section{Cell morphology}

MC3T3-E1 cells observed by light microscopy after 4 days incubation with AA/GP displayed classical cuboidal appearance (Fig. 2a,b), typical of osteoblasts, that did not change with time. $50 \mu \mathrm{M}$ melatonin rapidly increased cell density. Though the majority of cells conserved a cuboidal appearance, sparse ramified cells appeared from day 8 (Fig. 2c,d).

AA/GP treated primary cells had mostly cobblestonelike features (Fig. 2e), with interspersed ramified cells (Fig. 2f).

Addition of ATRA $(10 \mu \mathrm{M}$ in MC3T3-E1 cells and $5 \mu \mathrm{M}$ in primary cells) completely changed the morphology of both cell populations; as soon as 4 days in the cell line and 2 days in primary cells, ramifications extended from the cell body and progressively increased in number and complexity (Fig. 2g-j).

By AFM - which provides high resolution images of the cell surface in the absence of alterations coming from additional manipulation/staining procedures - the complexity of cell ramifications produced by ATRA treatment was more evident (Fig. 3a), and it was possible to appreciate their non-homogenous conformation, characterised by periodical enlargements (Fig. 3b-d); secondary processes departed from primary processes, and ramifications from neighbour cells frequently interconnected.

Staining of filamentous actin by rhodamine-labelled phalloidin highlighted the differences among treatments, because cell processes of ATRA-treated cells were labelled by phalloidin (Fig. 3e-f). In AA/GP- and melatonin-treated cobblestone cells actin was organised in stress fibres and appeared reinforced at the cell periphery, emphasising the rounded shape (Fig. 3g). In primary cells, actin staining also evidenced the presence of sparse ramified cells among the cobblestone ones (Fig. 3h).

TEM allowed further comparison and evaluation of morphological details. After 15 days of treatment, MC3T3-E1 cells incubated either with AA/GP or melatonin had particularly developed Golgi apparatus and endoplasmic reticulum (Fig. 4a,b). Numerous rounded areas of collagen accumulation occupied the cell body (Fig. 4a-c) and large numbers of collagen fibres were also clearly detectable in the extracellular space (Fig. 4d). MC3T3-E1 cells treated for 15 days with ATRA displayed ramified projections that were laterally interacting with other ramifications or with the cell body of neighbour cells (Fig. $4 \mathrm{e}-\mathrm{h})$. Lateral adhesions were mostly made by adherens junctions. No intracellular collagen accumulation was found, nor was extracellular matrix deposition detectable.

\section{Cell proliferation}

Incorporation of BrdU was higher in melatonin-treated MC3T3-E1 cells than in AA/GP cells, though the difference was not statistically significant. ATRA treatment decreased significantly cell proliferation in both the cell line and primary cells (Fig. 5).

\section{Matrix production and mineralisation}

Matrix mineralisation, as assessed by alizarin red staining, was most abundant in melatonin-treated cells, whereas it was completely absent in ATRA-incubated cells (Fig. 6 ). The result was confirmed also by spectrophotometry measurement of alizarin red extracted from all cell types, which was minimal in ATRA-treated cells, and the highest in melatonin-incubated cells.

Alkaline Phosphatase was barely detectable in cells treated with ATRA (Fig 7a,d) as compared with cells incubated with melatonin or AA/GP (Fig 7b,e). mRNA was concordantly lower in ATRA treated cells (Fig. 7c,f).

Collagen type I immunofluorescence revealed the presence of abundant collagen fibrils inside and outside MC3T3-E1 cells treated with AA/GP and melatonin (Fig. $8 \mathrm{a}, \mathrm{b})$. ATRA limited the expression of collagen type I to the intracellular compartment only, in a perinuclear location (Fig. 8c). In-cell ELISA showed constant expression levels of collagen type I in AA/GP and melatonin-treated cells, whereas the amount of collagen progressively decreased with time in ATRA-incubated cells (Fig. 8d). The mRNA of collagen type I alpha1 chain was greatly reduced in ATRAtreated cells as compared to AA/GP and melatonin-treated cells (Fig. 8e).

Osteocalcin release into the supernatant of melatonintreated cells progressively increased with time, whereas it was almost absent from the medium collected from ATRA-treated cells (Fig. 9).

\section{Other markers}

Osteoprotegerin was diffusely expressed by AA/GP-treated cells, whereas only a few ATRA-treated cells were positive (Fig. 10). 

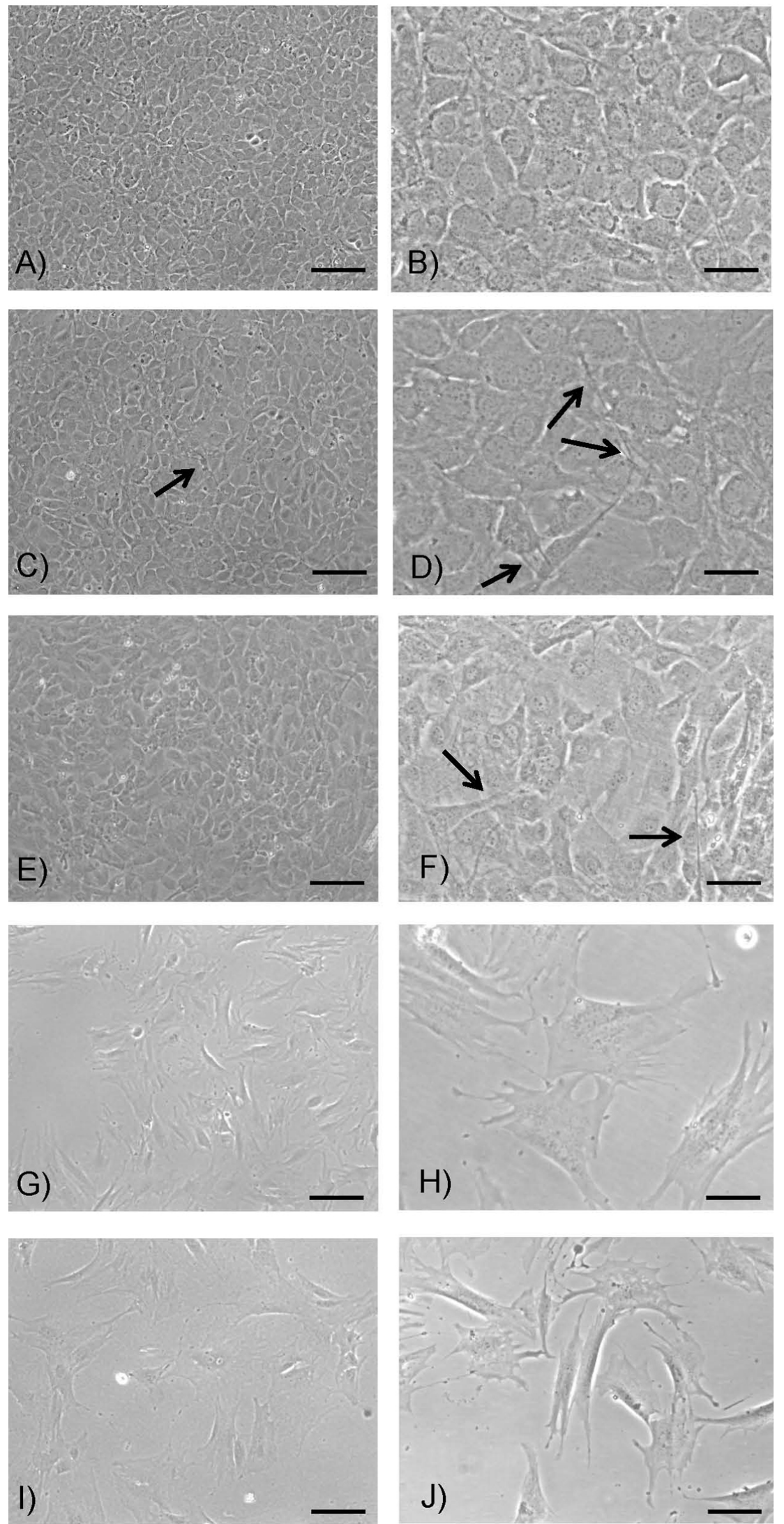

Fig. 2. Light microscopy. Homogeneous cuboidal appearance of MC3T3-E1 cells after 10 days incubation with AA/GP, as shown at low (A, scale bar $200 \mu \mathrm{m})$ and higher magnification (B, scale bar $62.5 \mu \mathrm{m})$. In the presence of melatonin, the majority of cells remain cuboidal, and interspersed ramified cellular elements can be observed (C, scale bar $200 \mu \mathrm{m}$, arrow), which are more evident at higher magnification (D, scale bar $62.5 \mu \mathrm{m}$, arrows). A cuboidal appearance characterises the majority of primary osteoblasts after 5 days of AA/GP treatment (E, scale bar $200 \mu \mathrm{m}$ ). Sparse ramified cells are present (F, scale bar $62.5 \mu \mathrm{m}$, arrows). After 10 days of ATRA treatment $(\mathbf{G}$, scale bar $200 \mu \mathrm{m} ; \mathbf{H}$, scale bar $62.5 \mu \mathrm{m})$, MC3T3-E1 cells display a more elongated shape and numerous dendrites. Similar morphological features characterise primary cells after 5 days of ATRA incubation (I, scale bar $200 \mu \mathrm{m}$; J, scale bar $62.5 \mu \mathrm{m}$ ). 

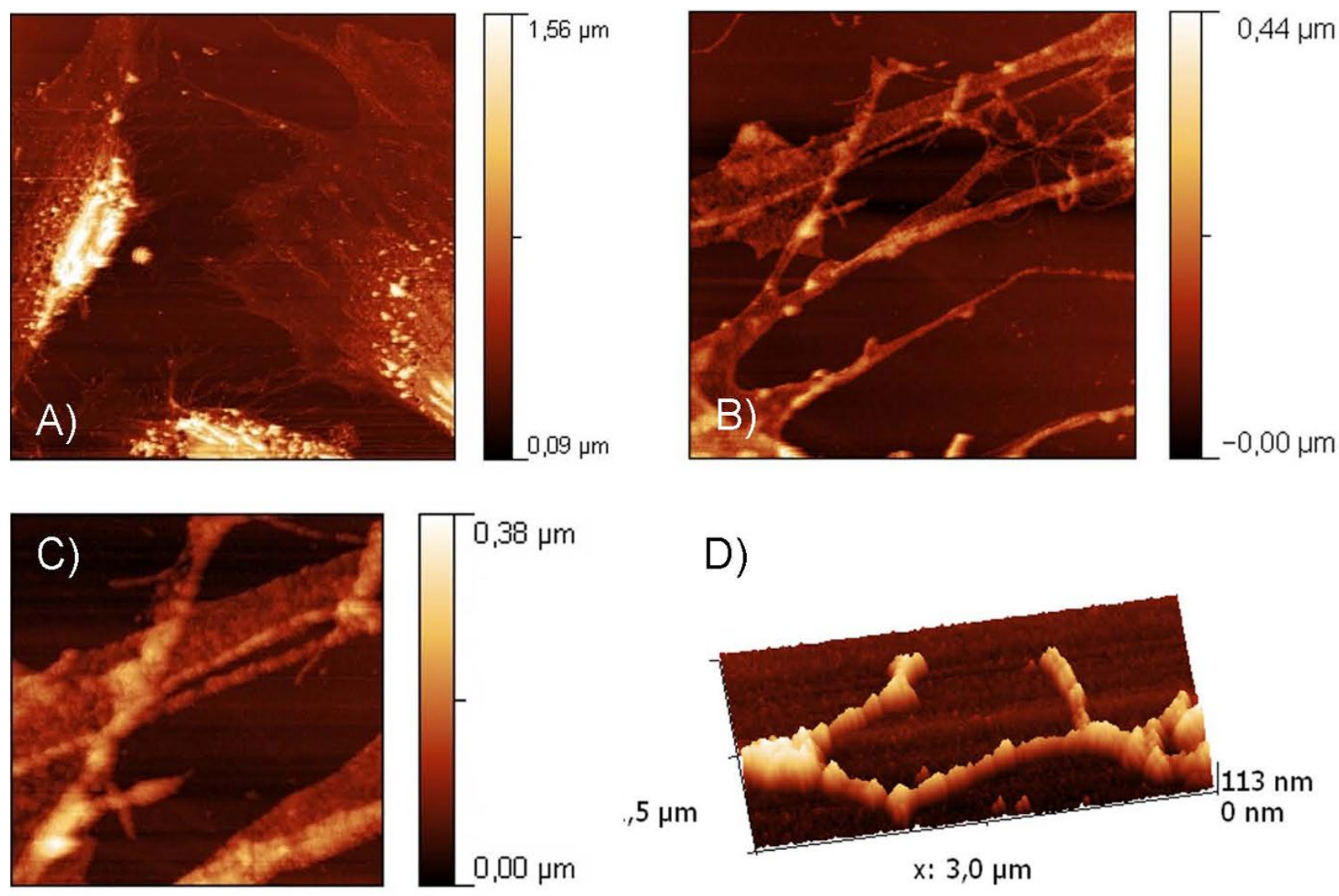

D)
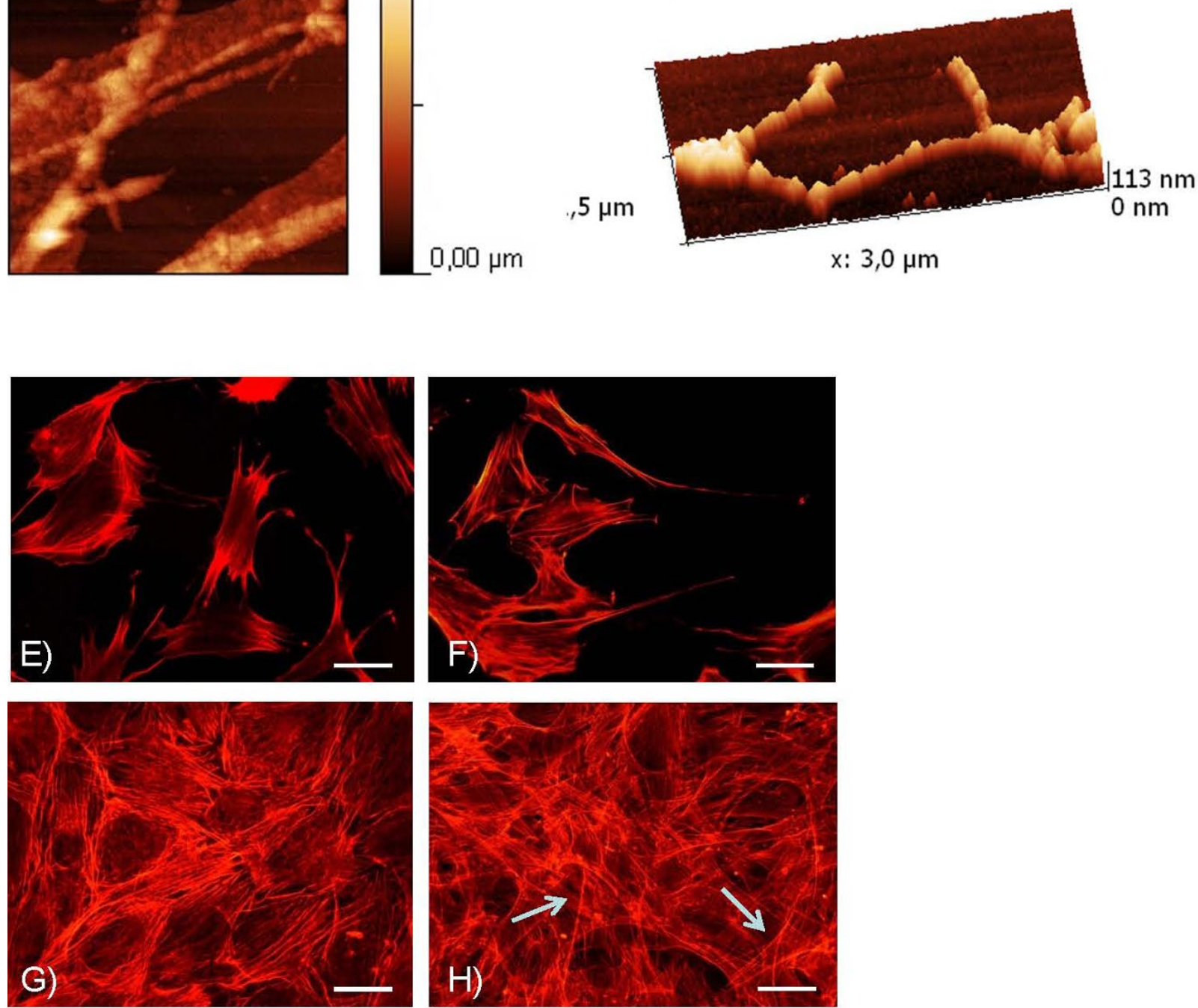

Fig. 3. Atomic force microscopy and actin filament staining. Panels (A-D): Images were taken after MC3T3-E1 cells were treated with ATRA for 10 days, and show interactions between ramifications from different cells $(\mathbf{A}, \mathbf{B})$. The surface appearance of cell processes is evident, with periodic enlargements along the length $(\mathbf{B}, \mathbf{C})$, which are especially evident in the 3D representation (D). Panels (E-H): actin filaments are identified by Rhodamine-phalloidin staining. Filamentous actin appears as a major component of cell processes in MC3T3-E1 (E) and primary (F) ATRA-treated cells. Cortical actin and stress fibres are evident in MC3T3-E1 cells incubated with melatonin (G), as well as in AA/ GP-treated primary cells $(\mathbf{H})$. Arrows indicate presence of actin along cell processes. Scale bars: $50 \mu \mathrm{m}$. 

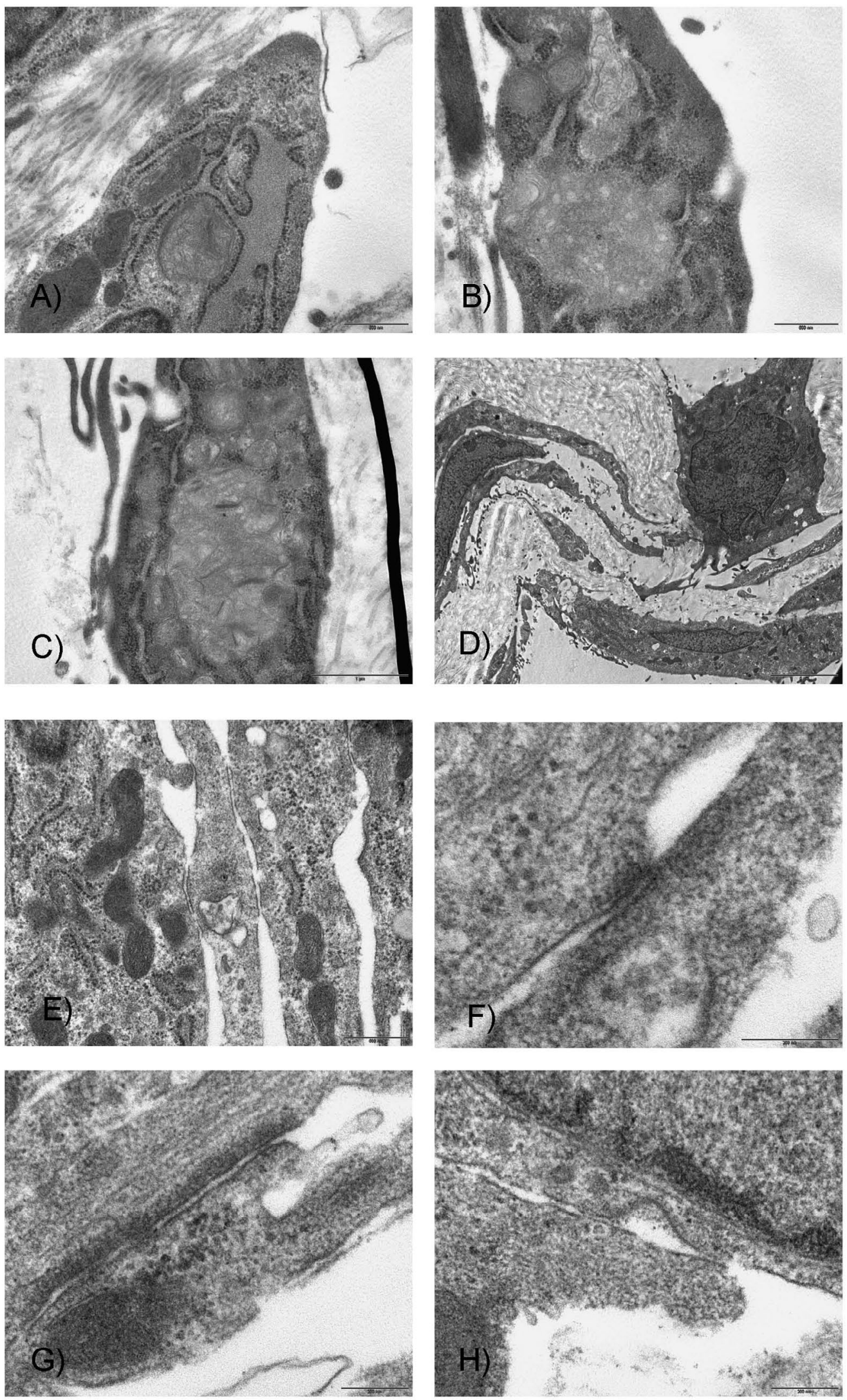

Fig. 4. Transmission electron microscopy (TEM). TEM images of MC3T3-E1 cells were taken after 15 days of treatment in the three different experimental conditions. The cytoplasm of a AA/GP treated cell displays abundant endoplasmic reticulum and accumulation of collagen fibrils (A). Outside the cell, parallel collagen fibres can be observed. Larger cytoplasmic areas of collagen accumulation can be seen in panels $(\mathbf{B})$ and $(\mathbf{C})$, showing cells treated with $\mathrm{AA} / \mathrm{GP}(\mathbf{B})$ and melatonin (C). At lower magnification (D), melatonin-treated cells are surrounded by abundant extracellular matrix. In panel $(\mathbf{E})$, the cytoplasm of a cell treated with ATRA for 15 days is flanked by a series of cell processes, forming multiple adhesions. At higher magnification (F-H), details of these adhesion sites can be appreciated, with the morphological features of adherens junctions. Scale bars: (A), (B), (E): $500 \mathrm{~nm} ;(\mathbf{C}): 1 \mu \mathrm{m} ;(\mathbf{D}): 5 \mu \mathrm{m} ;(\mathbf{F}, \mathbf{G}, \mathbf{H}): 200 \mathrm{~nm}$. 


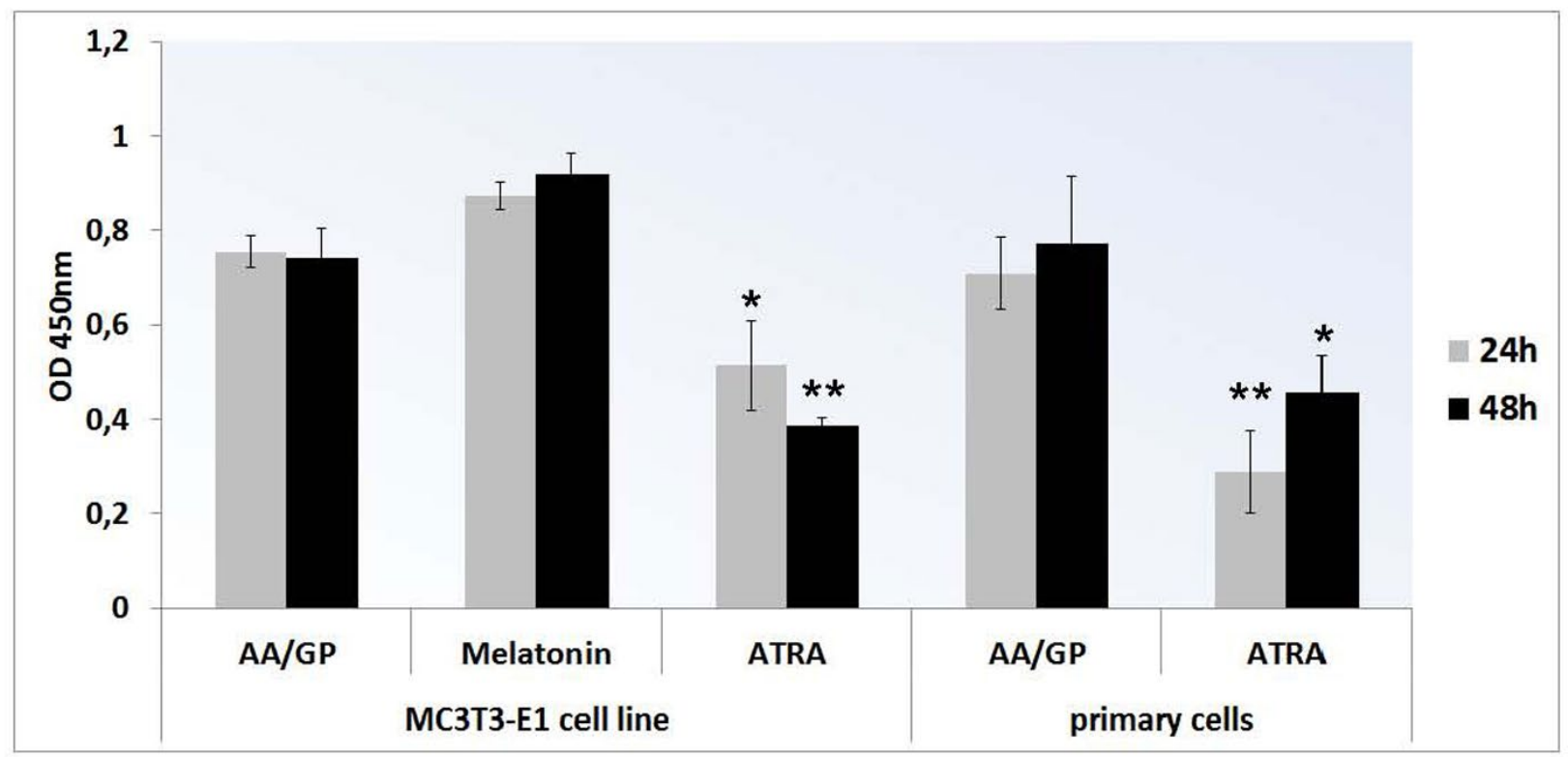

Fig. 5. BrdU incorporation. BrdU incorporation, evaluated at 24 and $48 \mathrm{~h}$ on MC3T3-E1 and primary cells, is significantly reduced in both cell populations after ATRA incubation. Asterisks indicate significant values, obtained by comparing each ATRA-treated group to the corresponding AA/GP and melatonin-treated groups: $*=p<0,05$; $* *=p<0.01$

Connexin 43 was detectable by immunofluorescence in all groups of cells (Fig. 11a-d) at any time point. In ramified cells the molecule was observed along and at the tip of cell processes (Fig. 11b-d). In-Cell ELISA (Fig. 11e) and Western Blot (Fig. 11f) showed the presence of the protein in almost equal amounts in all cell types, supporting the presence of differences only in its subcellular distribution.

E11/gp38, assessed by immunofluorescence and western blot, was expressed by the majority of MC3T3-E1 cells after 5 days of ATRA incubation, and decreased after 10 days (Fig. 12a-c). In primary cells, it appeared after 2 days of ATRA treatment and was almost undetectable at 7 days. The protein was not expressed at any time by AA/ GP-treated MC3T3-E1 cells (Fig. 12c,d), whereas sparse ramified cells, found either among melatonin-treated MC3T3-E1 cells (Fig. 12c,e) and AA/GP-treated primary osteoblasts, were mildly positive.

Sclerostin mRNA and protein were consistently expressed only by ATRA-treated cells (Fig. 13a-f). Immunostaining revealed intense cytoplasmic expression and the presence of positive dots along cell processes.

\section{Differentially expressed genes}

By immunofluorescence, a strong FGF23 positivity was detectable only in ATRA-treated cells (Fig. 14a-k). By Western Blot FGF23, barely expressed by cells incubated for 5 days with AA/GP, showed a clear band in ATRAtreated cells, and a mild expression in melatonin-incubated cells (Fig. 15a). The amount of secreted FGF23, as detected by ELISA-test conducted on the supernatant, increased with time in all cell types, and was mostly abundant in ATRA-treated cells (Fig. 15b). FGF23 mRNA, assessed by Real Time RT-PCR, showed the highest expression in ATRA-treated MC3T3-E1 cells at 5 days of incubation (Fig. 15c).
Compared to AA/GP and melatonin, ATRA-treated cells displayed mRNA upregulation of several bone morphogenetic proteins, such as Bmp2 (Fig. 16a), and metalloproteinases.

Finally, ATRA-treated cells disclosed increased expression of a series of osteocyte-specific molecules, such as Dmp1, Phex, and Tuft1 (Fig. 16b-d). In parallel, typical markers of the osteoblasts, such as Runx2, were downregulated (Fig. 16e).

\section{Discussion}

Investigation of osteocyte biology has always suffered from the limited availability of in vitro models and, until recently, from the difficulty of characterising these cells by reliable specific markers. For these reasons, osteoblasts were used as surrogate cells over a long period before the osteocyte-like cell line MLO-Y4 (Bonewald, 1999) was made available. Undoubtedly, this cell line remains the best and most widely used in vitro osteocyte model.

Isolation and culture of primary osteocytes, first obtained from chick bones (Van der Plas and Nijweide, 1992; Nijweide et al., 2003), and subsequently from rat calvaria (Gu et al., 2006), represented a major breakthrough in the field; primary cells better resemble the in vivo situation, but their isolation generates only a small number of cells per procedure, and cell purity relies to a large extent on individual expertise, therefore the method is currently used only by a limited number of laboratories.

More recently, mature osteocytes have been obtained by inducing terminal differentiation of osteoblasts by progressive embedding in a three-dimensional mineralised matrix (Boukhechba et al., 2009; Krishnan et al., 2010), that constitutes a more physiological environment but is 

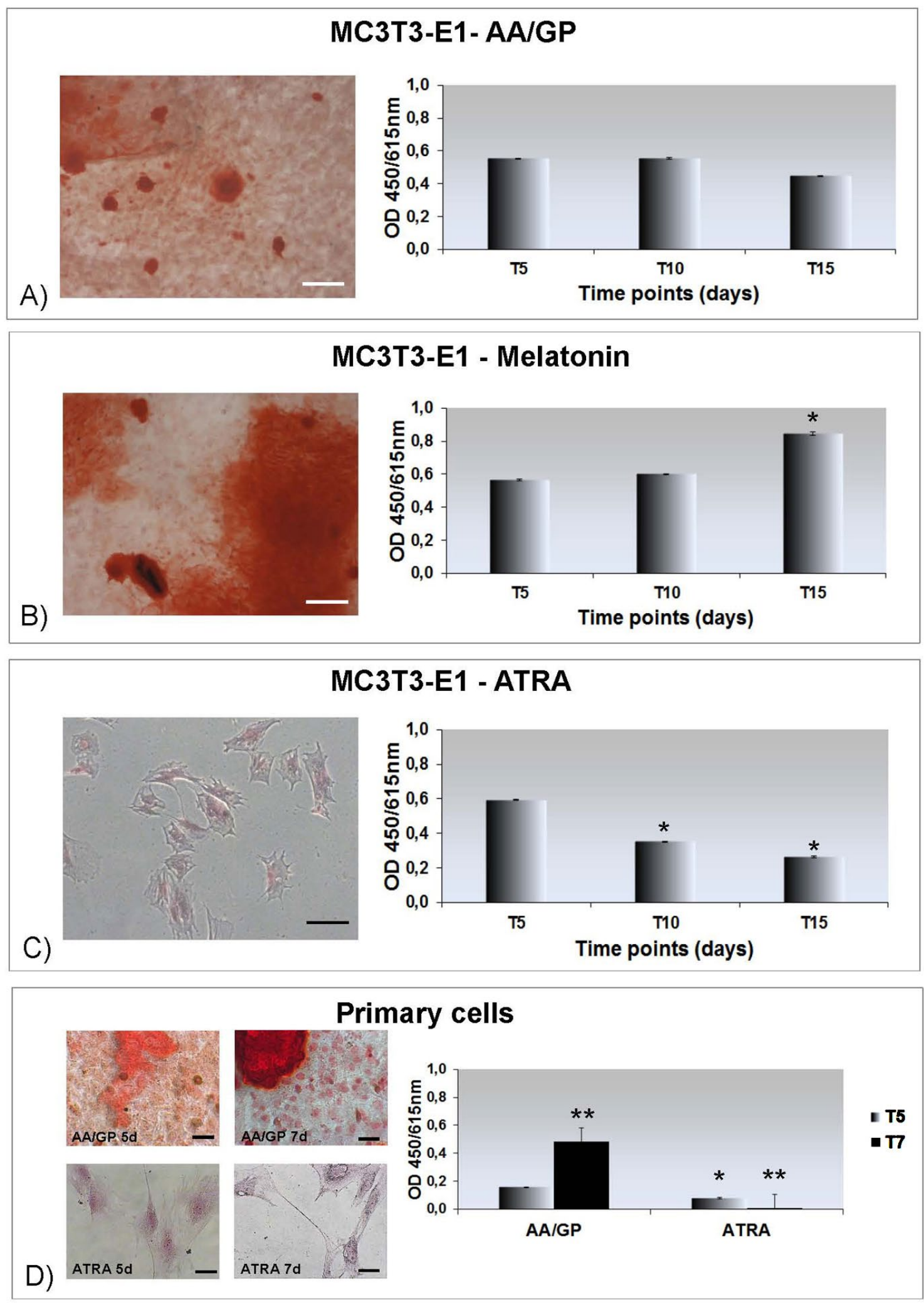

Fig. 6. Matrix mineralisation. Alizarin red staining was performed according to the protocol described in the method section, and observed at various time points. Panels (A-C): MC3T3-E1 cells. Left panels show light microscopy images of alizarin red staining after 10 days of treatment, and right panels show the quantification of alizarin extracted from cells at various time points $(5,10,15$ days) and normalised to the cell number. All data demonstrate an increase of matrix mineralisation in melatonin-treated cells, as compared to AA/GP treated cells. ATRA treatment abolishes the production of matrix. Scale bars: A, B: $100 \mu \mathrm{m}$; C: $50 \mu \mathrm{m}$. Panel (D): primary cells. Light microscopy shows the progressive increase of matrix mineralisation after 5 and 7 days of AA/GP incubation (upper images), the profound reduction of staining after 5 days of ATRA, and the staining disappearance after 7 days (lower images). These findings are confirmed by alizarin extraction (graph). Scale bars: upper images $75 \mu \mathrm{m}$; lower images $25 \mu \mathrm{m}$. Asterisks indicate significant differences: $*=p<0,05 ; * *=p<0.01$. 

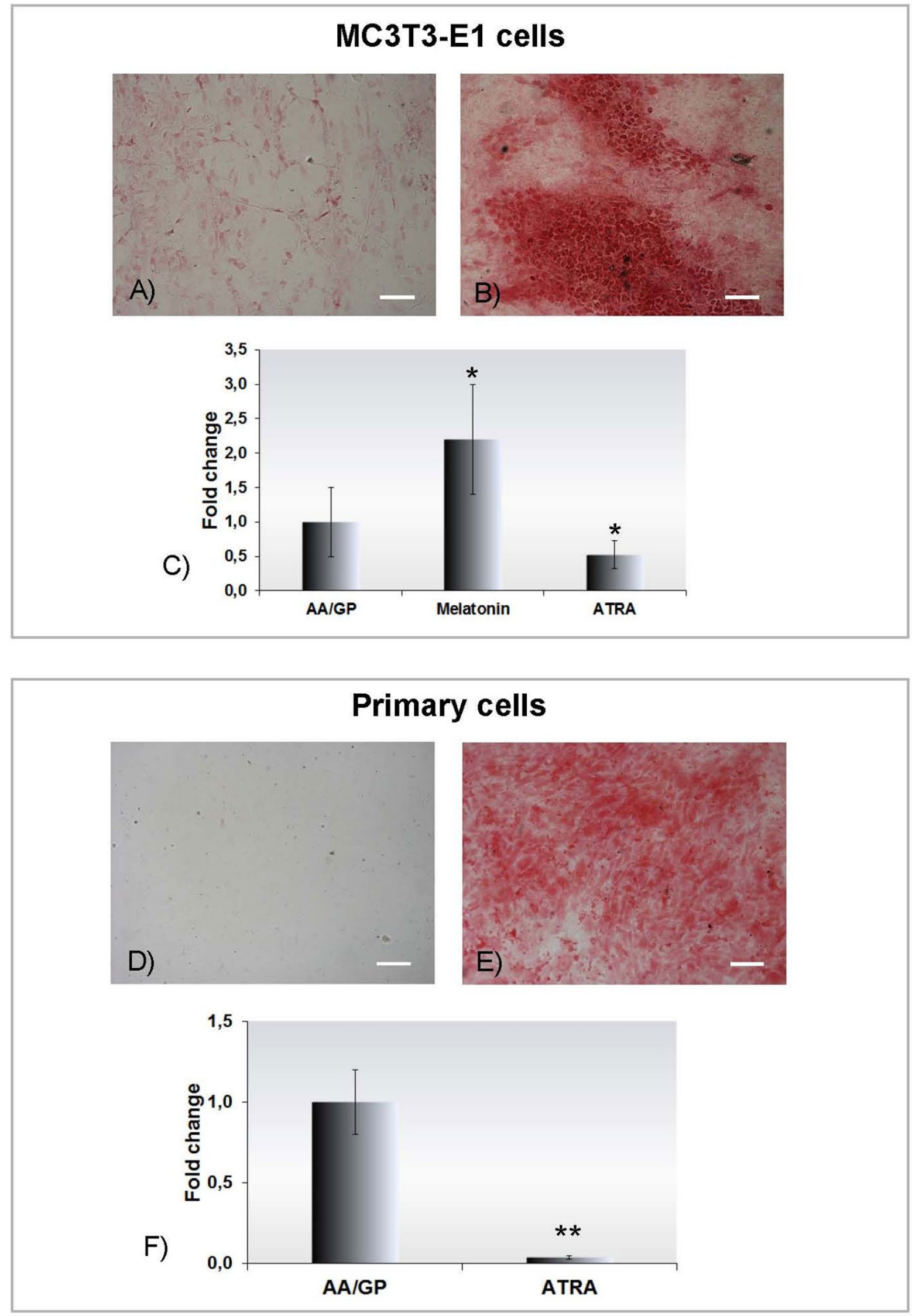

Fig. 7. Alkaline phosphatise. MC3T3-E1 cells barely express alkaline phosphatase after 10 days of ATRA treatment (A), whereas the staining is strong after 10 days of melatonin incubation (B). Real time RT-PCR data (C) show that mRNA expression for the enzyme is the highest in melatonin-incubated cells. In primary cells, the staining is almost absent after treatment with ATRA for 7 days (D), whereas positivity is diffusely present in AA/GP-incubated cells at the same time point (E). Accordingly, real time RT-PCR shows minimal mRNA expression in ATRA-treated cells (F). Asterisks indicate significant differences: $*=p<0,05 ; * *=p<0.01$. 


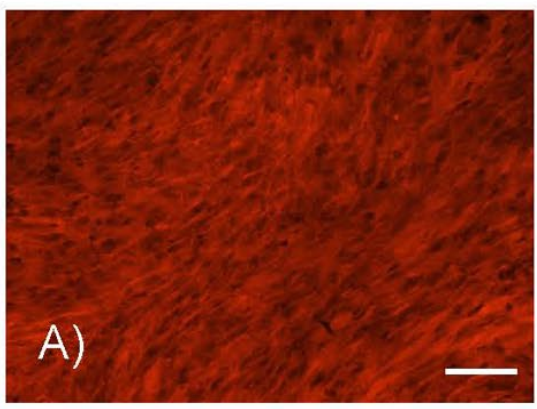

AA/GP

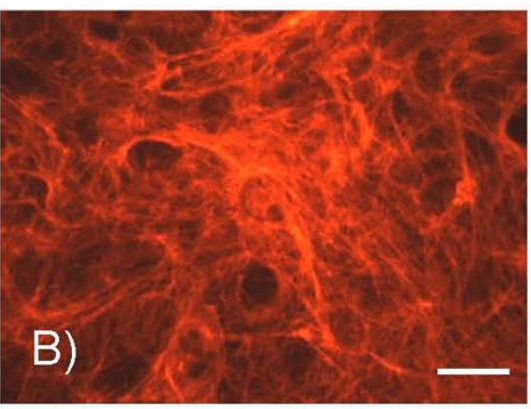

Melatonin

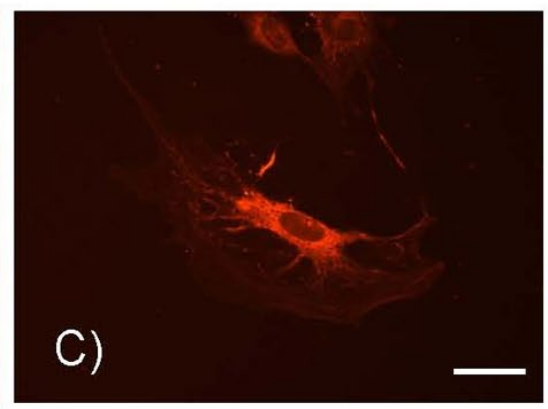

ATRA
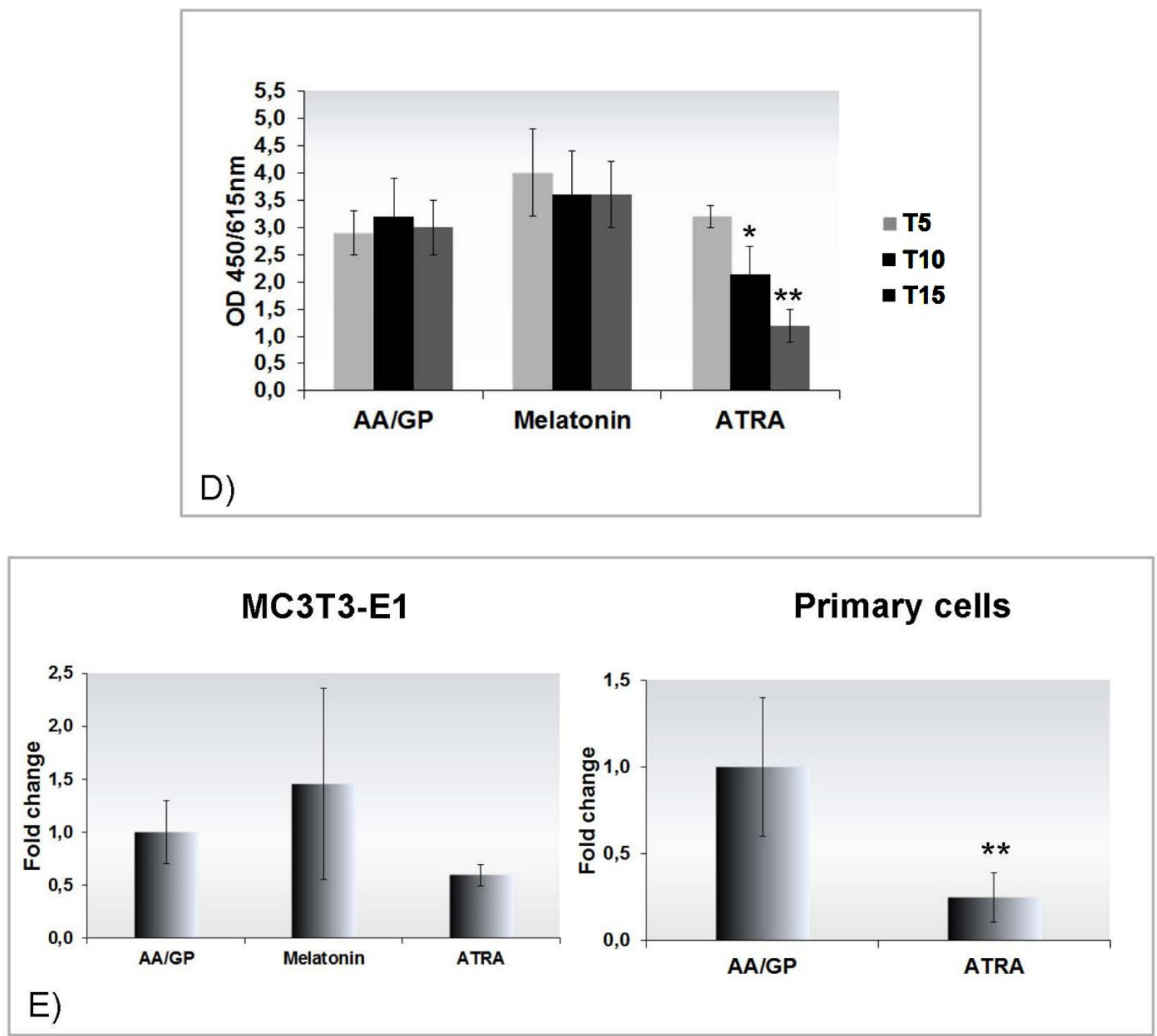

Fig. 8. Collagen Type I. Immunostaining for collagen type I shows diffuse positivity in MC3T3-E1 AA/GP treated cells (A, scale bar $200 \mu \mathrm{m})$, and increased intensity in melatonin-treated cells (B, scale bar $50 \mu \mathrm{m})$. Panel (C) shows the perinuclear staining of a cell incubated with ATRA for 10 days, and the absence of extracellular staining (scale bar $50 \mu \mathrm{m}$ ). In-cell ELISA results for collagen type I are displayed in panel (D) and confirm the highest expression of collagen in melatonin-treated cells and the progressive reduction of staining along ATRA incubation. Panel (E): Real-time RT-PCR of collagen type I alpha1 chain confirms downregulation of this molecule in ATRA-treated MC3T3-E1 (left graph) and primary cells (right graph). Asterisks indicate significant differences: $*=p<0.05 ; * *$ $=p<0.01$. 
Fig. 9. Osteocalcin release. Results from ELISA tests conducted on the supernatant collected from melatonin (A) and ATRA (B) treated MC3T3-E1 cells at various time points (first day of treatment $=\mathrm{T} 0,10$ days $=\mathrm{T} 10,15$ days $=\mathrm{T} 15$, and 20 days $=\mathrm{T} 20)$. Release of osteocalcin is similar $(<0.25 \mathrm{ng} /$ $\mathrm{mL}$ ) at the first day of treatment, then progressively increases with melatonin incubation, whereas it is almost abolished by ATRA. Asterisks indicate significant differences: $*=$ $p<0.05 ; * *=p<0.01$.

Fig. 10. Osteoprotegerin. The molecule, diffusely expressed by primary cells incubated with AA/ GP (panel A), is positive on a few cells after ATRA treatment (B). Scale bars $50 \mu \mathrm{m}$. Panel (C) shows that expression of OPG mRNA, quantified by Real Time RT-PCR on primary cells, is higher in AA/GP treated cells. $* *=p<0.01$.
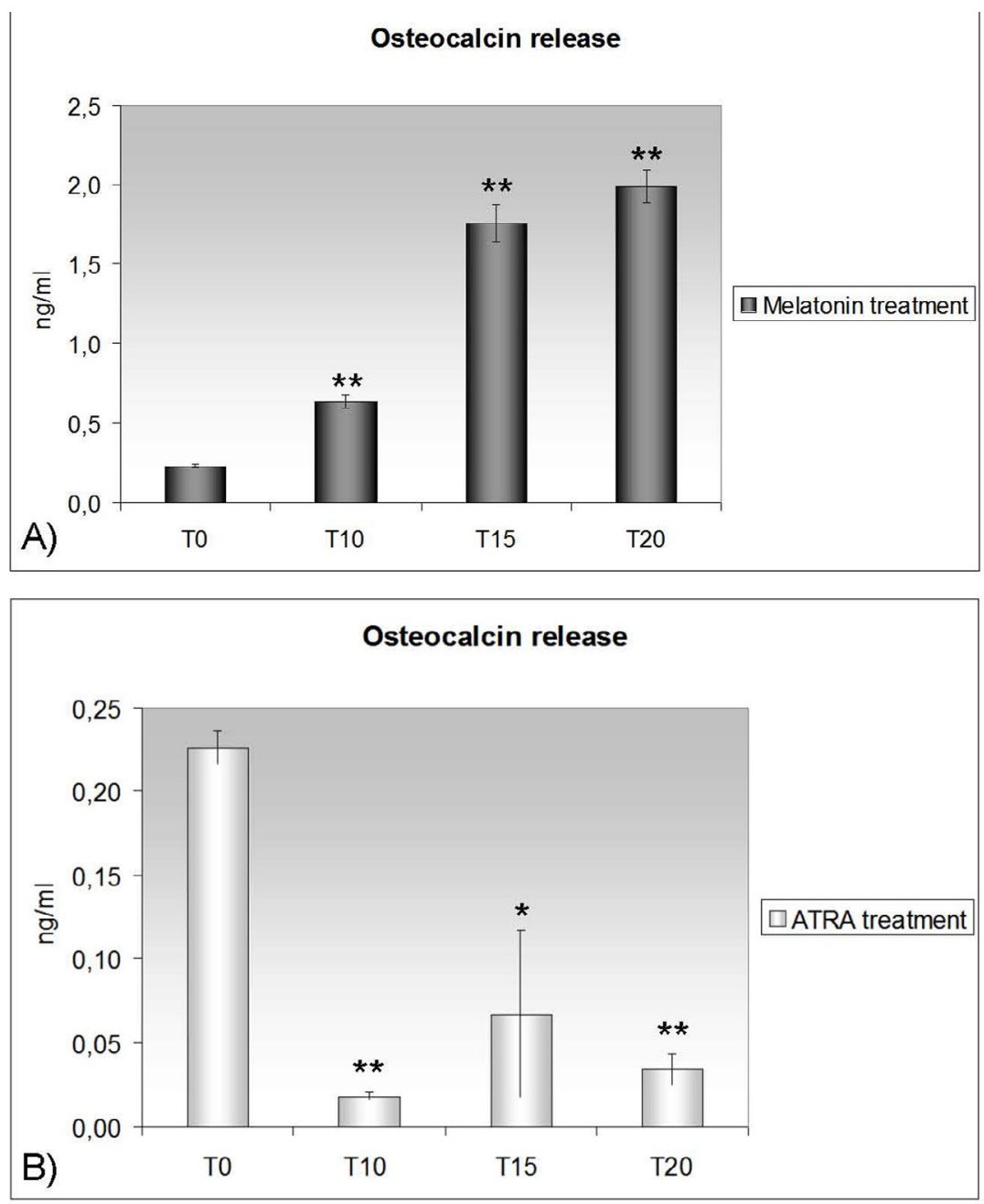

Primary cells
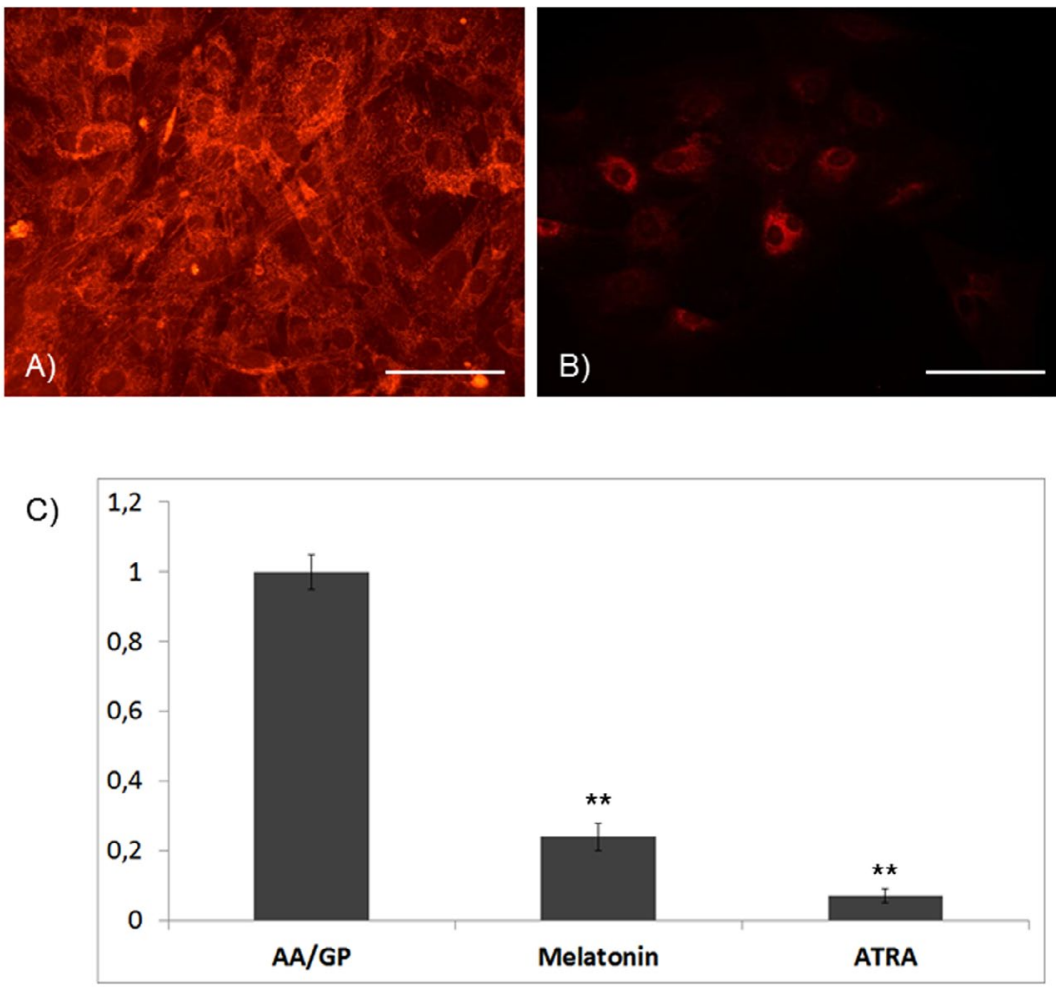

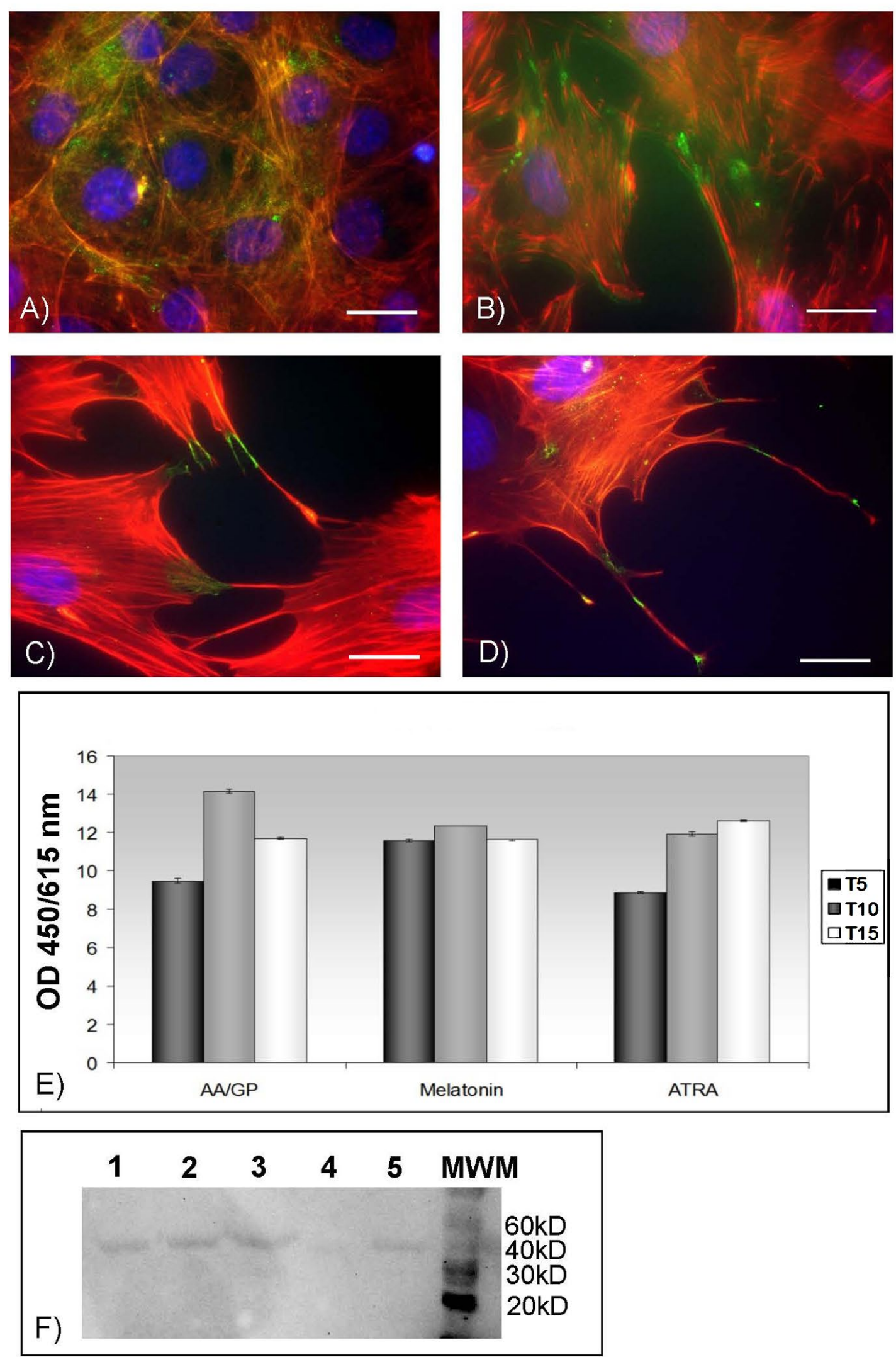

Fig. 11. Connexin 43. MC3T3-E1 cells incubated for 10 days with AA/GP (A) mainly show cytoplasmic Connexin 43 (Cx43) positivity (in green), whereas in ramified cells from melatonin treatment $(\mathbf{B})$ and especially from ATRA treatment (C, D) Cx43 is present along and at the tip of cell processes, mostly alternating with actin (red), and showing partial co-localisation (yellow dots). Scale bars $50 \mu \mathrm{m}$. DAPI (blue) nuclear counterstaining. No major quantitative changes of Cx43 staining can be appreciated by in-cell ELISA technique $(\mathbf{E})$, nor among cell types nor among different time points $(5$ days $=\mathrm{T} 5$, black bars, 10 days $=\mathrm{T} 10$, grey bars, 15 days $=\mathrm{T} 15$, white bars $)$. Panel $(\mathbf{F})$ : Western Blot analysis confirms the presence of $\mathrm{Cx} 43$-positive bands in protein lysates from AA/GP (lane 1,5), melatonin (lane 2) and ATRA (lane 3 ) cells after 10 days incubation. Line 4 = negative control. 

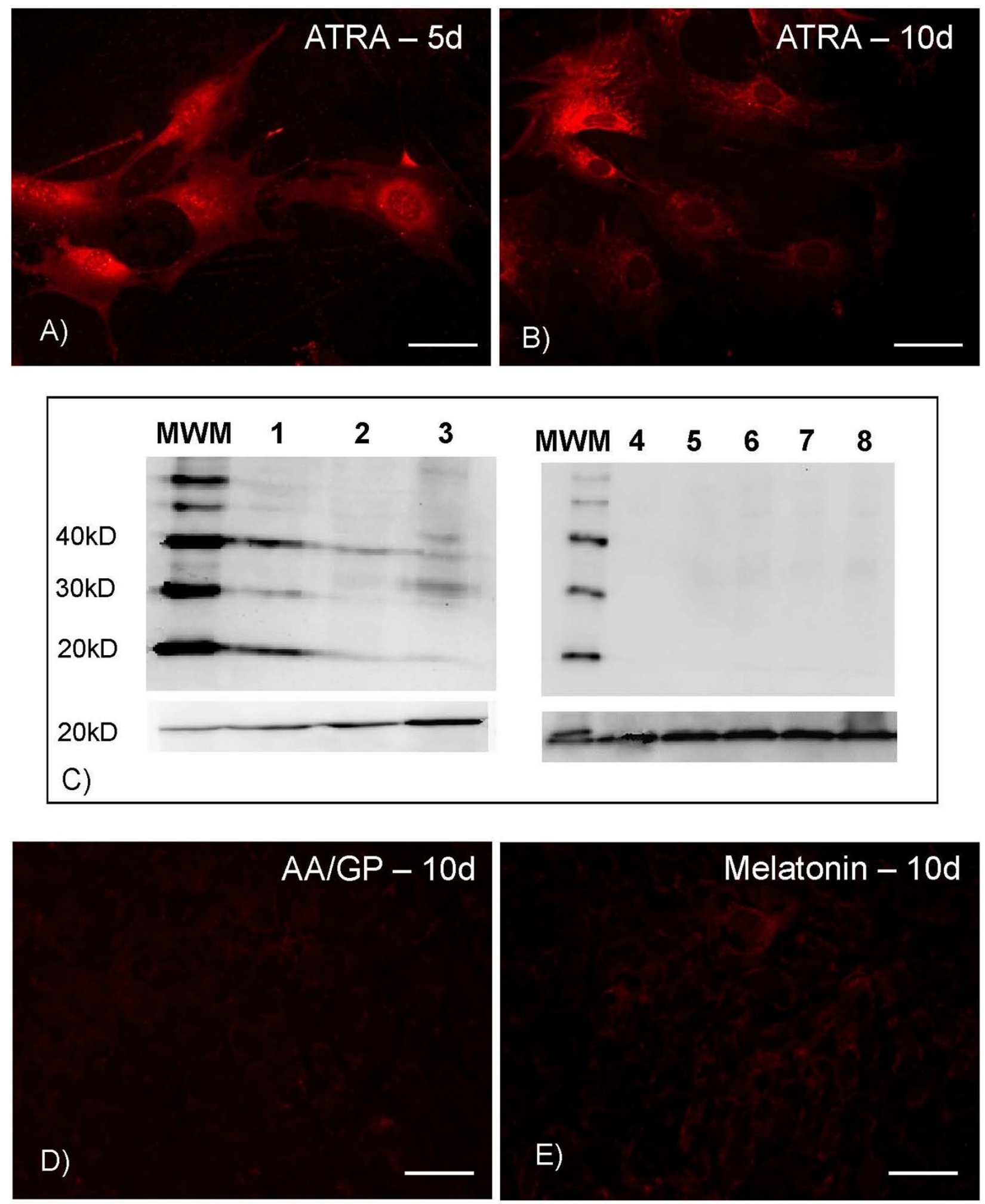

Fig. 12. E11/gp38. A strong expression of E11/gp38 is shown by ATRA-treated MC3T3-E1 cells at 5 days (A), and decreases at 10 days of incubation (B). Scale bars $50 \mu \mathrm{m}$. Panel (C), left blot, displays western blot results, showing evident bands of both 40 (mature protein) and $20 \mathrm{kDa}$ (immature form) from protein extracts of ATRA-treated cells. The strongest bands appear at 5 days of treatment (lane 1) and the intensity progressively declines at 10 (lane 2) and 15-days (lane 3). The right blot displays barely detectable bands at $40 \mathrm{kDa}$ and $20 \mathrm{kDa}$ in protein extracts from AA/ GP cells at 10 (lane 4) and 15 days (lane 5), and melatonin-treated cells at 5 (lane 6), 10 (lane 7) and 15 days (lane 8). Cofilin (lower blots) is shown as loading control. Immunofluorescence of AA/GP-treated MC3T3-E1 cells (D) is almost negative, and a mild positivity can be observed in cells incubated with melatonin (E). Scale bars $100 \mu \mathrm{m}$. 


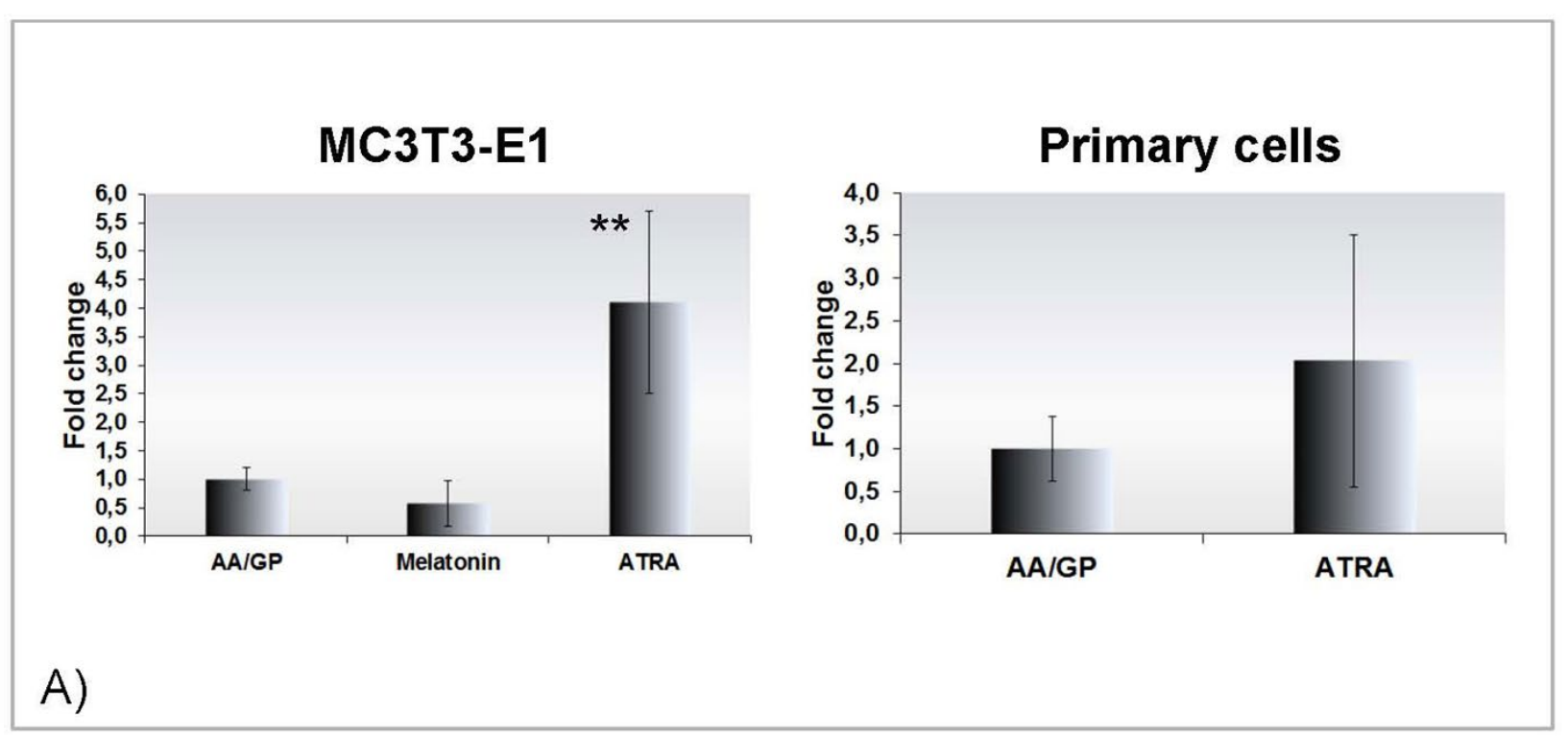

MC3T3-E1
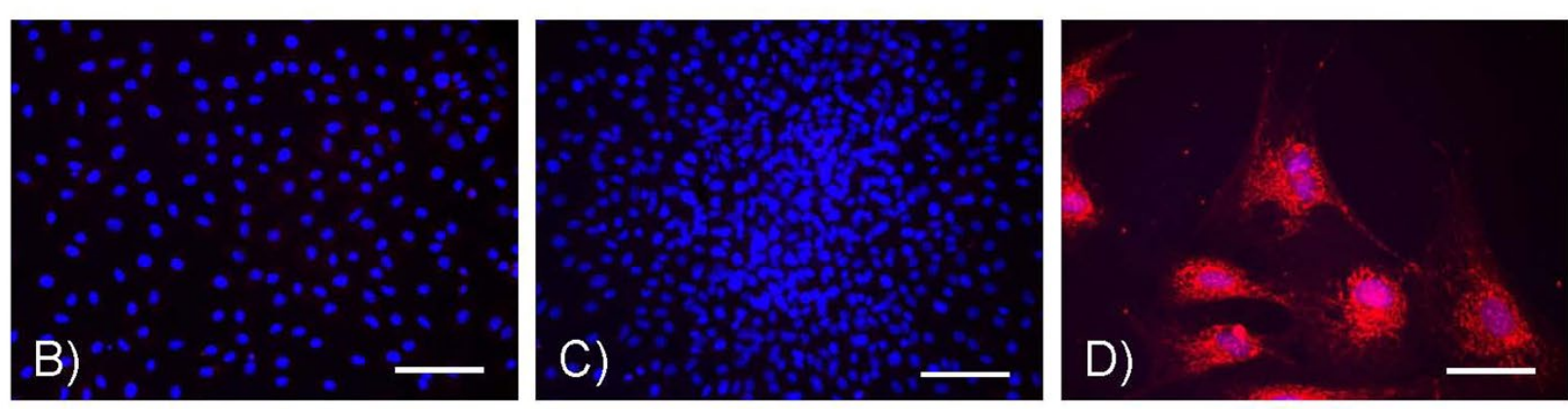

\section{Primary cells}
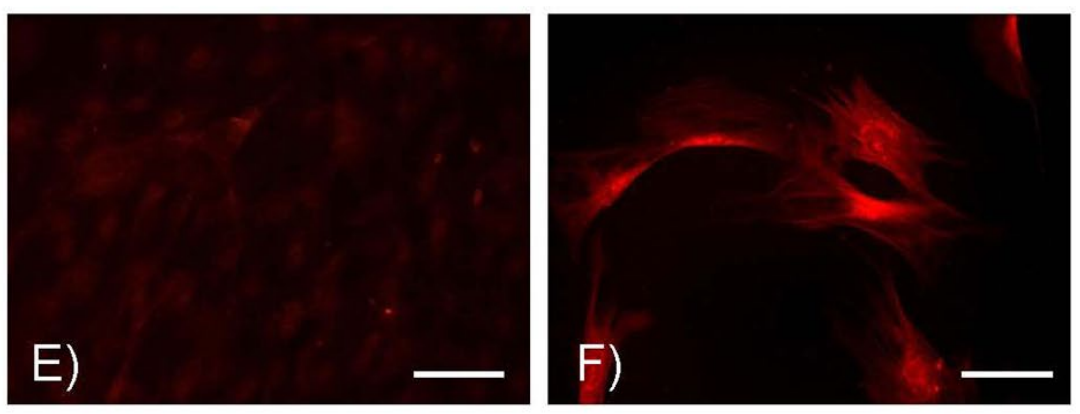

Fig. 13. Sclerostin. Sclerostin mRNA, panel (A), as obtained from the Real Time RT-PCR array experiments conducted on MC3T3-E1 (left graph) and primary cells (right graph), is more expressed in ATRA-treated cells. ** $=p<0.01$. Immunostaining for sclerostin is negative in MC3T3-E1 cells incubated with AA/GP $(\mathbf{B})$ or melatonin (C), whereas evident positivity is detected in the cytoplasm and along cell processes of cells incubated with ATRA (D). In primary cells incubated with AA/GP, sclerostin is almost completely negative (E), whereas the staining is clearly detectable after ATRA incubation (F). Scale bars $200 \mu \mathrm{m}(\mathbf{B}, \mathbf{C}), 100 \mu \mathrm{m}(\mathbf{E}), 50 \mu \mathrm{m}(\mathbf{D}, \mathbf{F})$. 
MC3T3-E1
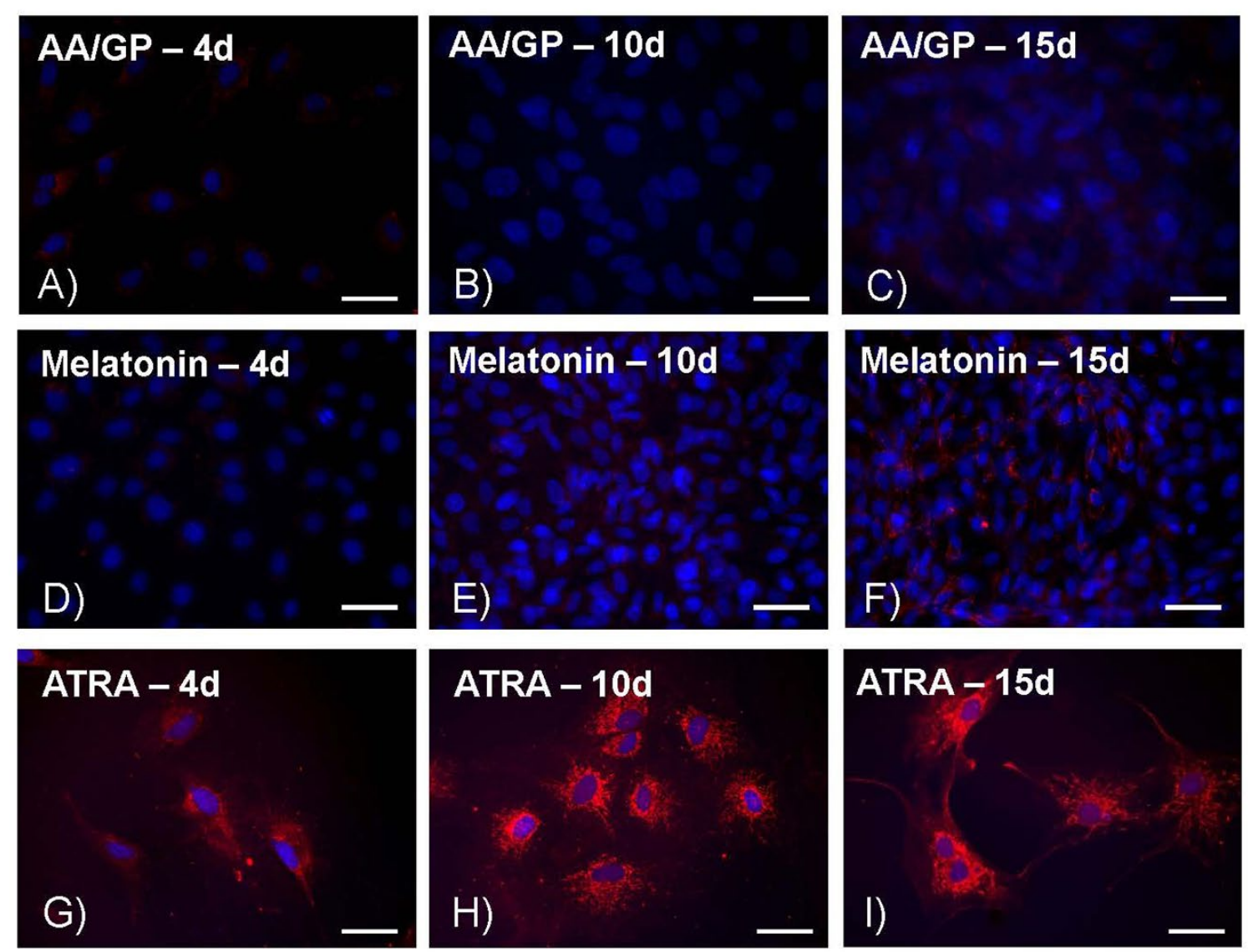

\section{Primary cells}

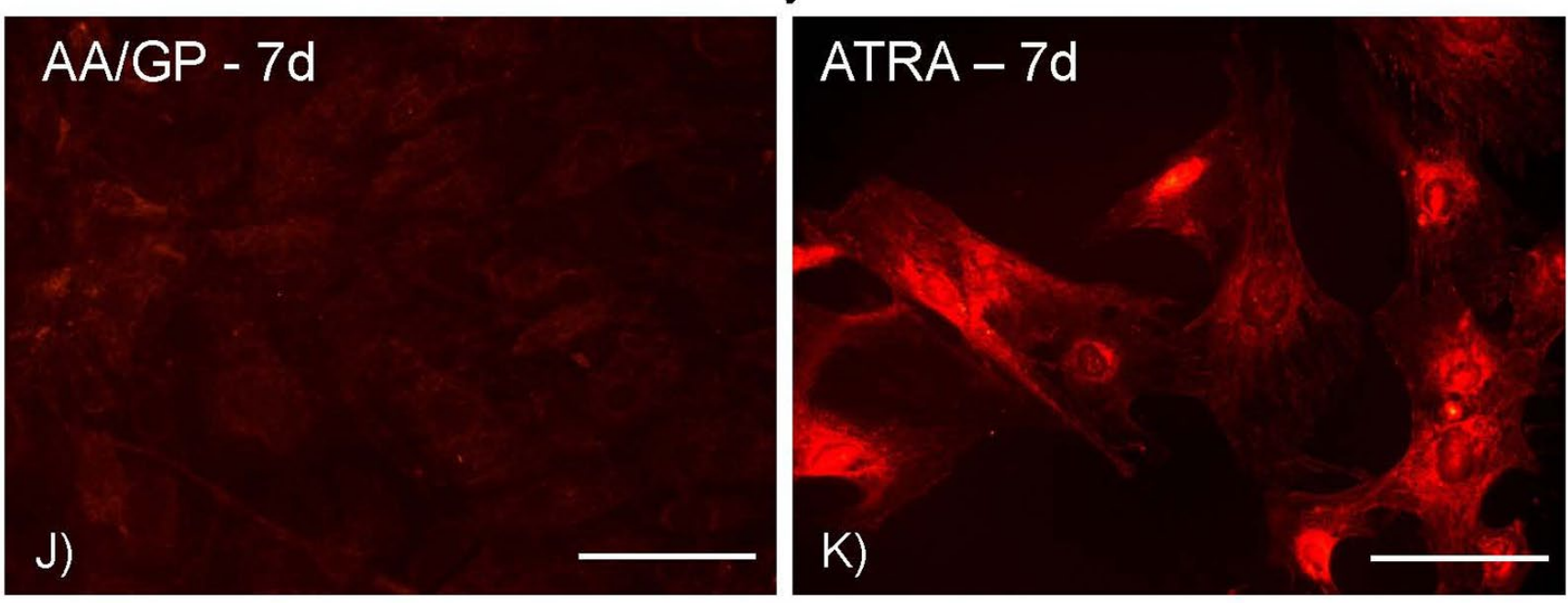

Fig. 14. FGF23. MC3T3-E1 cells incubated with AA/GP are FGF23-negative at any time points (A: 4 days, B: 10 days; C: 15 days), as well as melatonin-treated cells at 4 (D) and 10 days incubation (E), whereas a scattered staining can be observed after 15 days of melatonin treatment (F). FGF23 immunostaining is always present in ATRA-treated cells and seems to increase from $4(\mathbf{G})$ to 10-15 days incubation (H-I). Primary cells incubated with AA/GP are almost completely negative $(\mathbf{J})$, whereas FGF23 staining is evident after ATRA treatment $(\mathbf{K})$. Scale bars: $100 \mu \mathrm{m}(\mathbf{A}, \mathbf{D}, \mathbf{E}, \mathbf{F}) ; 50 \mu \mathrm{m}(\mathbf{B}, \mathbf{C}, \mathbf{G}, \mathbf{H}, \mathbf{I}, \mathbf{J}, \mathbf{K})$. 


\section{MC3T3-E1}
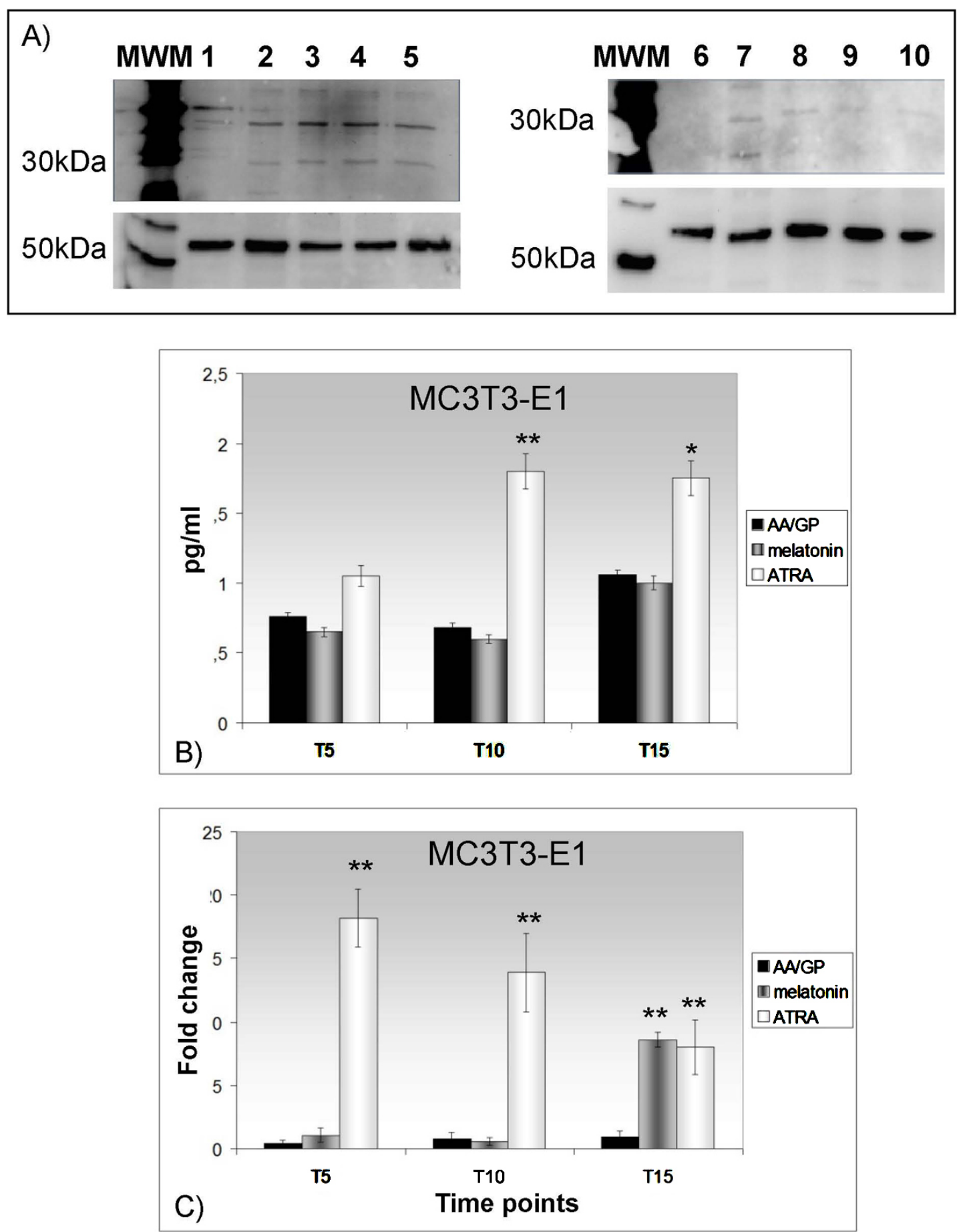

Fig. 15. FGF23. Panel (A): by western blot a band of $30 \mathrm{kDa}$, corresponding to the predicted molecular weight, and other bands at 15 and $60 \mathrm{kDa}$, can be detected. The left blot shows no specific band from AA/GP treated cells (15 days, lane 1) and the presence of defined bands from ATRA-treated cells at 4 (lane 2), 5 (lane 3), 10 (lane 4), and 15 days (lane 5) incubation. In the right blot no band can be observed in lane 6, corresponding to AA/GP treated cells (10 days), whereas a specific band is present in lanes 7-10, corresponding to melatonin-treated cells at 15 (lane 7), 10 (lane 8), 5 (lane 9) and 4 (lane 10) days incubation. Tubulin is shown (lower blots) as loading control. Panel (B) displays the results of the ELISA test conducted on MC3T3-E1 cell supernatant, expressed as pg/mL. FGF23 is released into the supernatant, though in different amounts, from all cell types, and the quantity increases with time (5, 10, 15 days). ATRA-treated cells (white bars) release the highest amounts of FGF23 at any time point. Panel (C): Real time RT-PCR results from mRNA extracted from MC3T3-E1 cells at different time points. The mRNA for FGF23 is most abundant in ATRA-treated cells at 5 days and declines with time (white bars). The opposite occurs in melatonin-incubated cells, where a larger amount of FGF23 mRNA can be detected at 15 days incubation (grey bars). AA/GP cells have the lowest amounts of mRNA at any time points (black bars). Asterisks indicate significant differences: $*=p<0,05 ; * *=p<0.01$. 

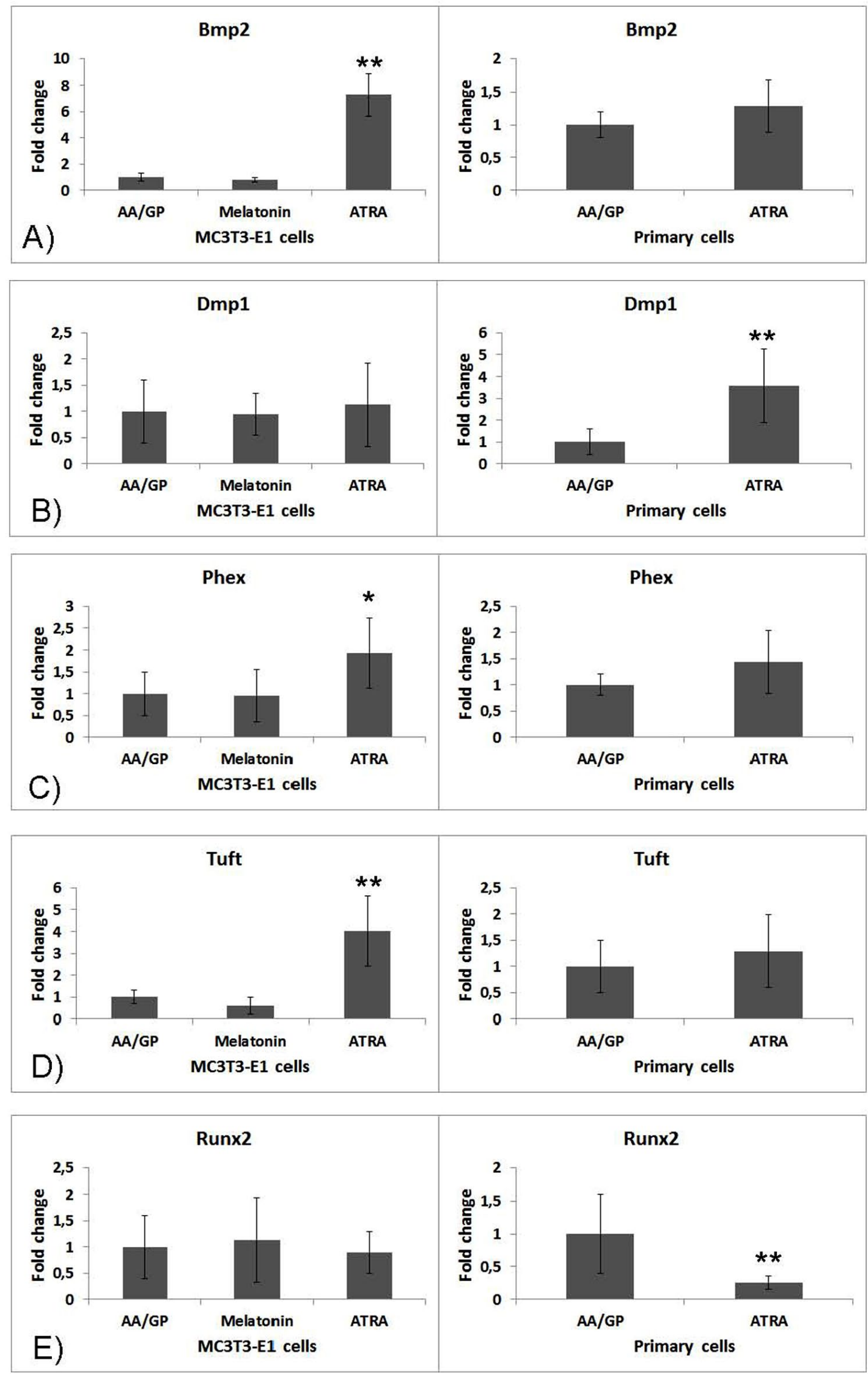

Fig. 16. Real Time RT-PCR results. The graphs show some of the molecules differentially expressed by MC3T3-E1 (graphs on the left) and primary cells (graphs on the right) in the different treatment conditions, as detailed in the Material and Methods section. In both cell populations, ATRA treatment induces the expression of several molecules with known relevance to osteocyte biology, such as Bmp2 (A), Dmp1 (B), Phex (C), and Tuft1(D), and downregulates the expression of molecules typical of osteoblasts, such as Runx2 (E). Asterisks indicate significant differences: * $=p<0,05 ; * *=p<0.01$. 
an obstacle to subsequent research applications. It is true that matrix mineralisation (Irie et al., 2008), as well as low oxygen tension (Hirao et al., 2007), are physiological triggers of osteocyte maturation. However, a methodology avoiding these two conditions could increase feasibility and extend the use of the cells.

Our proposed method, that consists of adding retinoic acid to osteoblasts derived from initial maturation of the MC3T3-E1 cell line or to primary osteoblasts, is simple and highly reproducible.

Among molecules recently proposed to induce an osteocyte-like phenotype, the multifunctional cytokine Oncostatin $\mathrm{M}$ has to be stably transfected by lentiviral particles to achieve complete osteocyte differentiation from the rat osteosarcoma OSRGA cell line and from primary rat calvaria cells (Brounais et al., 2009). Also, mature osteocytes have been obtained by adding fibroblast growth factor-2 (FGF-2) to MC4 cells (Gupta et al., 2010). Compared to these methods, retinoic acid addition is simpler than transfection and less expensive than FGF2.

With a series of preliminary experiments we determined that the starting cell number is a critical factor, conditioning proper formation of multiple dendrites and intercellular contacts. A too high plating cell density affects complexity and extension of cell processes, whereas too low numbers result in loss of intercellular adhesions, leading to cell suffering and death. Similar results were observed in other cell types, where cell density profoundly influenced the phenotype (Bauer et al., 2008; Sessarego et al., 2008; Turncliff et al., 2006).

Our method is highly reproducible, in both primary cells and the cell line; murine MC3T3-E1 cells, particularly the clones able to produce mineralised extracellular matrix, are largely in use and unanimously considered a biologically relevant model of osteoblast development because their maturation has numerous molecular similarities with the process in vivo (Quarles et al., 1992). Importantly, when the method is applied to primary cells, adjustment of ATRA dosage and daily monitoring of cell morphology are highly advised, because of the variability incidental to primary cells and the higher sensitivity to ATRA, as compared to the cell line.

It is well known that one of the most important ongoing changes during osteoblast transformation into osteocytes is the change of shape, from a polygonal cell to a ramified cell type, which is first detectable at the stage of osteoid osteocyte (Dallas and Bonewald, 2010). ATRA-incubated cells display ramifications as soon as after two days of treatment. As it occurs in primary osteocytes (Tanaka-Kamioka et al., 1998), dendrites are highly enriched in actin filaments. The peculiar morphology of these ramifications, with periodical enlargements, highly resembles that of other highly ramified cells (Wang et al., 2011), such as neuronal cells, when observed by AFM or scanning electron microscopy.

Connexin43 (Cx43) is the most abundant connexin in bone cells. Multiple lines of evidence have established its important role in function and survival of both osteoblasts and osteocytes (Stains et al., 2003), which is in line with our results, showing $\mathrm{Cx} 43$ in all groups of cells, independent of treatment. The extension of dendrites produced by
ATRA incubation affects the location of $\mathrm{Cx} 43$, that can be observed along and at the tip of cell processes. We were not able to identify complete gap junctions in any of our cell types by electron microscopy, and we did not find published data displaying by electron microscopy complete gap junctions in cultured bone cells. However, it is well known that connexons can function as gap junction hemichannels, being active without pairing with apposing connexons (Civitelli, 2008), and in in vitro conditions this configuration could be sufficient to maintain proper intercellular communication and response.

Since its first characterisation and cloning, E11/ gp38 (also known as podoplanin, T1A, GP36, GP40, OTS8, AGGRUS, and PA2.26) was selectively detected in osteocytes and pre-osteocytes, where its role can be relevant to development of cell dendrites (Zhang et al., 2006). Accordingly, we did not observe E11/gp38 in preosteoblasts and AA/GP incubated cells, though we did find a mild positivity in melatonin-treated cells and in the sparse ramified cells that are present among primary osteoblasts. In agreement with its predicted function, E11/ gp38 peaks at the beginning of ATRA treatment, when the development of cell processes is particularly active, and progressively declines during further cell maturation.

In parallel, extracellular matrix deposition and mineralisation are rapidly abolished in ATRA-incubated cells, as shown by the absence of extracellular collagen fibres and negativity of alizarin red staining. These events are confirmed by decrease of alkaline phosphatase and collagen type I, and progressive reduction of osteocalcin release. Furthermore, ATRA reduces osteoprotegerin, an important inhibitor of osteoclastogenesis and bone resorption (Udagawa et al., 2000), and the osteoblastspecific transcription factor Runx2 (Prince et al., 2001).

It is well known that osteocytes do not produce calcified matrix. Additionally, osteocytogenesis is now considered an active invasive process, during which degradation and remodelling of extracellular matrix are needed by osteocytes to enter the bone, and to form and maintain the extracellular environment of lacunae and canaliculi (Karsdal et al., 2004; Qing and Bonewald, 2009). According to these observations, our findings show increased mRNA levels of several matrix metalloproteinases and bone morphogenetic proteins in ATRA-treated cells.

Along this line of evidence, ATRA induces other wellknown osteocyte markers, such as Dmp1, Phex, Tuft1 and, most notably, sclerostin.

Dmp1 is a major regulator of mineralisation and has been shown to play a central role in the transition of osteoblasts/preosteocytes to osteocytes (Rios et al, 2005). Phex (PHosphate-regulating Endopeptidase homolog $\mathrm{X}$-linked), whose mutations in humans underlie X-linked hypophosphatemia, is a glycoprotein involved in the regulation of bone mineralisation. Interestingly, Phex deletion in mice causes a hypophosphatemic phenotype identical to that of Dmp1 null mice (Yuan et al., 2008). Tuft 1 , which is induced in response to hypoxia, is likely to be relevant to osteocyte survival in the microenvironment of the bone lacunae (Leiser et al., 2011).

It is our opinion that the strong expression of sclerostin by ATRA-treated cells further supports the mature 
osteocyte phenotype induced by retinoic acid. In fact, differently from sclerostin mRNA, which is found in many tissues, especially during embryogenesis, in vivo expression of the protein sclerostin has been reported only in osteocytes, in both adult murine and human bone (Poole et al., 2005). Sclerostin mRNA is increased in cultured osteoblasts after bone morphogenetic protein (Sutherland et al., 2004) and FGF2 stimulation (Gupta et al., 2010), and here we show a strong expression of both sclerostin mRNA and protein only in ATRA-treated cells.

Finally, ATRA-incubated cells display large amounts of FGF23, which is one of the most studied osteocyte products, because of its pivotal role in phosphate homeostasis (Yoshiko et al., 2007). According to the literature, FGF23 is also produced by osteoblasts (Strom and Jüppner, 2008). Instead, our data, showing no evidence of intracellular protein in AA/GP-incubated cells, and minimal presence in melatonin-treated cells, suggest only a mild production of this factor by mature osteoblasts. As it occurs in vivo, where the molecule is released into the circulation (Strom and Jüppner, 2008; Yoshiko et al., 2007), FGF23 is released by our cells into the supernatant. Concordant to the mRNA and protein results, the largest FGF23 amounts can be detected in the supernatant of cells incubated with ATRA. Further studies aimed at investigating the functional role of FGF23 and sclerostin in osteocytes will be facilitated by the endogenous production of these molecules in ATRA-treated cells.

In summary, our findings seem to demonstrate that treatment with retinoic acid generates a homogeneous population of mature osteocytes from the MC3T3-E1 cell line and from primary calvaria cells. Compared to other methods, our protocol seems to present several advantages, primarily the simple application and the high reproducibility. The process of osteocyte maturation can be studied in adequate numbers of cells from the initial spreading of processes through several steps that occur in a 10-day frame. As a further advantage, mature osteocytes are obtained in complete absence of surrounding mineralised matrix, allowing the application of unlimited molecular and functional assays.

\section{Acknowledgments}

Funding was provided by "Progetto a concorso Fondazione IRCCS Ospedale Maggiore Policlinico 2009-2010" to MD, by Associazione Bambino Nefropatico ABN, Milano, and by the grant 'Project Glomerulonephritis' in memory of Pippo Neglia.

\section{References}

Bauer CT, Shtridelman Y, Lema Tomé CM, Grim JQ, Turner CP, Tytell M, Macosko JC (2008) Intraneuronal vesicular organelle transport changes with cell population density in vitro. Neurosci Lett 441: 173-177.

Bonewald LF (1999) Establishment and characterization of an osteocyte-like cell line, MLO-Y4. J Bone Miner Metab 17: 61-65.
Bonewald LF (2011) The amazing osteocyte. J Bone Miner Res. 26: 229-238.

Boukhechba F, Balaguer T, Michiels JF, Ackermann K, Quincey D, Bouler JM, Pyerin W, Carle GF, Rochet N (2009) Human primary osteocyte differentiation in a 3D culture system. J Bone Miner Res 24: 1927-1935.

Brounais B, David E, Chipoy C, Trichet V, Ferré V, Charrier C, Duplomb L, Berreur M, Rédini F, Heymann D, Blanchard F (2009) Long term oncostatin M treatment induces an osteocyte-like differentiation on osteosarcoma and calvaria cells. Bone 44: 830-839.

Cheng F, Hulley P (2010) The osteocyte - a novel endocrine regulator of body phosphate homeostasis. Maturitas 67: 327-338.

Civitelli R (2008) Cell-cell communication in the osteoblast/osteocyte lineage. Arch Biochem Biophys 473: 188-192.

Cohen-Tanugi A, Forest N (1998) Retinoic acid suppresses the osteogenic differentiation capacity of murine osteoblast-like 3/A/1D-1M cell cultures. Differentiation 63: 115-123.

Dallas SL, Bonewald LF (2010) Dynamics of the transition from osteoblast to osteocyte. Ann N Y Acad Sci 1192: 437-443.

Dodig M, Kronenberg MS, Bedalov A, Kream BE, Gronowicz G, Clark SH, Mack K, Liu YH, Maxon R, Pan ZZ, Upholt WB, Rowe DW, Lichtler AC (1996) Identification of a TAAT-containing motif required for high level expression of the COL1A1 promoter in differentiated osteoblasts of transgenic mice. J Biol Chem 271: $16422-$ 16429.

Goldstein DJ, Rogers CE, Harris H (1980) Expression of alkaline phosphatase loci in mammalian tissues. Proc Natl Acad Sci USA 77: 2857-2860.

Gu G, Nars M, Hentunen TA, Metsikkö K, Väänänen HK (2006) Isolated primary osteocytes express functional gap junctions in vitro. Cell Tissue Res 323: 263-271.

Gupta RR, Yoo DJ, Hebert C, Niger C, Stains JP (2010) Induction of an osteocyte-like phenotype by fibroblast growth factor-2. Biochem Biophys Res Commun 402: 258-264.

Hirao M, Hashimoto J, Yamasaki N, Ando W, Tsuboi $\mathrm{H}$, Myoui A, Yoshikawa H (2007) Oxygen tension is an important mediator of the transformation of osteoblasts to osteocytes. J Bone Miner Metab 25: 266-276.

Irie K, Ejiri S, Sakakura Y, Shibui T, Yajima T (2008) Matrix mineralization as a trigger for osteocyte maturation. J Histochem Cytochem 56: 561-567.

Karsdal MA, Andersen TA, Bonewald L, Christiansen C (2004) Matrix metalloproteinases (MMPs) safeguard osteoblasts from apoptosis during transdifferentiation into osteocytes: MT1-MMP maintains osteocyte viability. DNA Cell Biol 23: 155-165.

Krishnan V, Dhurjati R, Vogler EA, Mastro AM (2010) Osteogenesis in vitro: from pre-osteoblasts to osteocytes: a contribution from the Osteobiology Research Group, The Pennsylvania State University. In Vitro Cell Dev Biol Anim 46: 28-35.

Leiser Y, Silverstein N, Blumenfeld A, Shilo D, Haze A, Rosenfeld E, Shay B, Tabakman R, Lecht S, Lazarovici P, Deutsch D (2011) The induction of tuftelin expression 
in PC12 cell line during hypoxia and NGF-induced differentiation. J Cell Physiol 226: 165-72.

Li M, Armelloni S, Ikehata M, Corbelli A, Pesaresi M, Calvaresi N, Giardino L, Mattinzoli D, Nisticò F, Andreoni S, Puliti A, Ravazzolo R, Forloni G, Messa P, Rastaldi MP (2011) Nephrin expression in adult rodent central nervous system and its interaction with glutamate receptors. J Pathol 225: 118-128.

Livak KJ, Schmittgen TD (2001) Analysis of relative gene expression data using real-time quantitative PCR and the 2(-Delta Delta C(T)) method. Methods 25: 402-408.

Marie PJ (2012) Fibroblast growth factor signaling controlling bone formation: an update. Gene 498: 1-4.

Mizutani K, Ikeda K, Kawai Y, Yamori Y (1998) Resveratrol stimulates the proliferation and differentiation of osteoblastic MC3T3-E1 cells. Biochem Biophys Res Commun 253: 859-863.

Nagasawa H, Takahashi S, Kobayashi A, Tazawa H, Tashima Y, Sato K (2005) Effect of retinoic acid on murine preosteoblastic MC3T3-E1 cells. J Nutr Sci Vitaminol (Tokyo) 51: 311-318.

Nijweide PJ, van der Plas A, Alblas MJ, Klein-Nulend J (2003) Osteocyte isolation and culture. Methods Mol Med 80: 41-50.

Paic F, Igwe JC, Nori R, Kronenberg MS, Franceschetti T, Harrington P, Kuo L, Shin DG, Rowe DW, Harris SE, Kalajzic I (2009) Identification of differentially expressed genes between osteoblasts and osteocytes. Bone 45: 682692.

Poole KE, van Bezooijen RL, Loveridge N, Hamersma H, Papapoulos SE, Löwik CW, Reeve J (2005) Sclerostin is a delayed secreted product of osteocytes that inhibits bone formation. FASEB J 19: 1842-1844.

Prince M, Banerjee C, Javed A, Green J, Lian JB, Stein GS, Bodine PV, Komm BS (2001) Expression and regulation of Runx2/Cbfa1 and osteoblast phenotypic markers during the growth and differentiation of human osteoblasts. J Cell Biochem 80: 424-440.

Qing H, Bonewald LF (2009) Osteocyte remodeling of the perilacunar and pericanalicular matrix. Int J Oral Sci 1: 59-65.

Quarles LD, Yohay DA, Lever LW, Caton R, Wenstrup RJ (1992) Distinct proliferative and differentiated stages of murine MC3T3-E1 cells in culture: an in vitro model of osteoblast development. J Bone Miner Res 7: 683-692.

Rios HF, Ye L, Dusevich V, Eick D, Bonewald LF, Feng JQ (2005) DMP1 is essential for osteocyte formation and function. J Musculoskelet Neuronal Interact 5: 325-327.

Ross SA, McCaffery PJ, Drager UC, De Luca LM (2000) Retinoids in embryonal development. Physiol Rev 80: 1021-1054.

Roth JA, Kim BG, Lin WL, Cho MI (1999) Melatonin promotes osteoblast differentiation and bone formation. J Biol Chem 274: 22041-22047.

Sánchez-Barceló EJ, Mediavilla MD, Tan DX, Reiter RJ (2010) Scientific basis for the potential use of melatonin in bone diseases: osteoporosis and adolescent idiopathic scoliosis. J Osteoporos 2010: 830231.

Sessarego N, Parodi A, Podestà M, Benvenuto F, Mogni M, Raviolo V, Lituania M, Kunkl A, Ferlazzo G, Bricarelli FD, Uccelli A, Frassoni F (2008) Multipotent mesenchymal stromal cells from amniotic fluid: solid perspectives for clinical application. Haematologica 93: 339-346.

Song HM, Nacamuli RP, Xia W, Bari AS, Shi YY, Fang TD, Longaker MT (2005) High-dose retinoic acid modulates rat calvarial osteoblast biology. J Cell Physiol 202: 255-262.

Stains JP, Lecanda F, Screen J, Towler DA, Civitelli R (2003) Gap junctional communication modulates gene transcription by altering the recruitment of $\mathrm{Sp} 1$ and $\mathrm{Sp} 3$ to connexin-response elements in osteoblast promoters. J Biol Chem 278: 24377-24387.

Stangenberg L, Schaefer DJ, Buettner O, Ohnolz J, Möbest D, Horch RE, Stark GB, Kneser U (2005) Differentiation of osteoblasts in three-dimensional culture in processed cancellous bone matrix: quantitative analysis of gene expression based on real-time reverse transcriptionpolymerase chain reaction. Tissue Eng 11: 855-864.

Strom TM, Jüppner H (2008) PHEX, FGF23, DMP1 and beyond. Curr Opin Nephrol Hypertens 17: 357-362.

Sutherland MK, Geoghegan JC, Yu C, Winkler DG, Latham JA (2004) Unique regulation of SOST, the sclerosteosis gene, by BMPs and steroid hormones in human osteoblasts. Bone 35: 448-454.

Suzawa M, Takeuchi Y, Fukumoto S, Kato S, Ueno N, Miyazono K, Matsumoto T, Fujita T (1999) Extracellular matrix-associated bone morphogenetic proteins are essential for differentiation of murine osteoblastic cells in vitro. Endocrinology 140: 2125-2133.

Tanaka-Kamioka K, Kamioka H, Ris H, Lim SS (1998) Osteocyte shape is dependent on actin filaments and osteocyte processes are unique actin-rich projections. J Bone Miner Res 13: 1555-1568.

Tian Y, Xu Y, Fu Q, He M (2011) Parathyroid hormone regulates osteoblast differentiation in a $\mathrm{Wnt} / \beta$-catenindependent manner. Mol Cell Biochem 355: 211-216.

Turncliff RZ, Tian X, Brouwer KL (2006) Effect of culture conditions on the expression and function of Bsep, Mrp2, and Mdr1a/b in sandwich-cultured rat hepatocytes. Biochem Pharmacol 71: 1520-1529.

Van der Plas A, Nijweide PJ (1992) Isolation and purification of osteocytes. J Bone Miner Res 7: 389-396.

Udagawa N, Takahashi N, Yasuda H, Mizuno A, Itoh K, Ueno Y, Shinki T, Gillespie MT, Martin TJ, Higashio K, Suda T (2000) Osteoprotegerin produced by osteoblasts is an important regulator in osteoclast development and function. Endocrinology 141: 3478-3484.

Wang D, Christensen K, Chawla K, Xiao G, Krebsbach PH, Franceschi RT (1999) Isolation and characterization of MC3T3-E1 preosteoblast subclones with distinct in vitro and in vivo differentiation/mineralization potential. J Bone Miner Res 14: 893-903.

Wang X, He D, Chen L, Chen T, Jin H, Cai J, Chen Y (2011) Cell-surface ultrastructural changes during the in vitro neuron-like differentiation of rat bone marrowderived mesenchymal stem cells. Scanning 33: 69-77.

Yuan B, Takaiwa M, Clemens TL, Feng JQ, Kumar R, Rowe PS, Xie Y, Drezner MK (2008) Aberrant Phex function in osteoblasts and osteocytes alone underlies murine X-linked hypophosphatemia. J Clin Invest 118: 722-734. 
Yoshiko Y, Wang H, Minamizaki T, Ijuin C, Yamamoto R, Suemune S, Kozai K, Tanne K, Aubin JE, Maeda N (2007) Mineralized tissue cells are a principal source of FGF23. Bone 40: 1565-1573.

Zhang K, Barragan-Adjemian C, Ye L, Kotha S, Dallas M, Lu Y, Zhao S, Harris M, Harris SE, Feng JQ, Bonewald LF (2006) E11/gp38 selective expression in osteocytes: regulation by mechanical strain and role in dendrite elongation. Mol Cell Biol 26: 4539-4552.

\section{Discussion with Reviewer}

Reviewer II: The possibility to obtain osteocyte in vitro in a reproducible way can be an extremely powerful method to study osteocytes. In this context, it is important to determine whether similar pattern of differentiation can be achieved using primary calvaria cells, since this will allow studying the effects of particular genes on osteocyte biology using cells derived from genetically modified mice. Please comment.

Authors: The proposed method can be applied also to primary cells, and our results seem to confirm that ATRA induces in mouse primary osteoblasts a similar pattern of differentiation as in the cell line. However, differently from the cell line, we observed that primary cells are more sensitive to ATRA. This, together with the inherent variability of primary cultures, must be taken into account at the very beginning of the procedure, to adapt ATRA dosages and times according to the specific cell population in use. In our experience, morphological daily monitoring is a reliable mean of evaluation.

Reviewer II: What is known about the presence of ATRA receptors in osteoblasts and osteocytes?

Authors: As for the presence of retinoic acid receptors on MC3T3-E1 cells, the first report we found dates back to 1996 (Chen et al., 1996, additional reference). Most studies on this subject, however, have been addressed on chondrocytes and we could not find any literature report about the expression of retinoic acid receptors in mature bone and osteocytes.

\section{Additional Reference}

Chen Y, Takeshita A, Ozaki K, Kitano S, Hanazawa S (1996) Transcriptional regulation by transforming growth factor beta of the expression of retinoic acid and retinoid $\mathrm{X}$ receptor genes in osteoblastic cells is mediated through AP-1. J Biol Chem 271: 31602-31606. 